\title{
Assessment of Failure and Cohesive Zone Length in Co-consolidated Hybrid C/PEKK Butt Joint
}

\author{
Ismet Baran $^{1 *}$, Laurent L. Warnet ${ }^{1}$, Remko Akkerman ${ }^{1}$ \\ ${ }^{1}$ Chair of Production Technology, Faculty of Engineering Technology, University of Twente, 7500AE, \\ Enschede, The Netherlands \\ *E-mail: i.baran@utwente.nl
}

\begin{abstract}
The failure mechanisms and the cohesive zone length (CZL) during fracture of recently developed butt jointed thermoplastic composite are evaluated in this paper. The laminated skin and the web were made of AS4/PEKK. The butt joint (filler) was injection molded from $20 \%$ short AS4 filled PEKK. The skin and web were co-consolidated together with the filler to form a hybrid butt joint structure. The crack initiation and propagation in the filler and the delamination at the skin-filler interface were captured using a high-speed camera. It was found from the experimental observations that the crack initiated in the filler and then propagated towards the skin-filler interface in less than $33 \mu$ s under three-point bending. A numerical model was developed using the finite element method in ABAQUS to predict the failure and CZL. The crack initiation and progression in the filler was predicted using the Virtual Crack Closure Techniques (VCCT) and the delamination at the skin-filler interface was modelled using the cohesive surfaces. The predicted stiffness of the specimen, the location of crack initiation and propagation as well as the force drop during delamination were in good agreement with experiments. The development of CZL was critically assessed and it was found that the CZL increases during delamination. The effect of interface strength and critical energy release rate on the CZL was investigated in the parameter analysis. Keywords: Co-consolidation; butt joint; failure analysis; FEM; cohesive zone length.
\end{abstract}




\section{Introduction}

High performance thermoplastic composites (TPCs) such as carbon fiber/poly(ether ether ketone) (C/PEEK) and carbon fiber/poly(ether ketone ketone) (C/PEKK) are preferred in aerospace and aircraft industries to boost the weight-to-strength ratio of composite structures. In particular, thermoplastic stiffened composites are currently being developed for primary aircraft components such as fuselage and torsion box at airplane tail. The application of TPCs has also been gradually increasing in the automotive industries owing to their high toughness, high damage tolerance and recyclability. The TPCs are manufactured using various techniques such as stamp forming, laser assisted tape placement (LATP), welding, injection molding, co-consolidation in autoclave, over-molding, etc. The TPCs have still been under development with novel material compositions and manufacturing techniques. There is a need for material characterization and better understanding of the processing conditions as well as mechanical performance [1-5]. The storage and loss moduli of a unidirectional carbon/PEEK specimens were determined in [1] in order to characterize the intra-ply shear behavior. The fracture toughness of a carbon/PPS (polyphenylene sulfide) was determined using the proposed mandrel peel test in [3] and the results were compared with the double cantilevered beam (DCB) tests. The randomly oriented strand/PEEK composites were characterized in [5] using a thermomechanical and dynamic mechanical analyzer to correlate the expansion and shrinkage of the composite with the process induced defects. The manufacturing process has a direct influence on the material properties of the final product such as fracture toughness, degree of cure, degree of crystallinity, elastic modulus and strength. To illustrate, Mode-I fracture toughness was found to be $60-80 \%$ higher for the LATP processed specimens than for the autoclave processed specimens in [6]. This is due to the fact that lower cooling rate in autoclave process yields in higher crystallinity level in the semi-crystalline PEEK polymer as compared with higher cooling rates in the LATP; and the higher the crystallinity level, the lower the fracture toughness $[7,8]$. It was conculded in [8] that the plastic deformation of the fast-cooled PEEK arising from high ductility was responsible for the improved interlaminar fracture toughness. On the other hand, an increase 
in the crsytallinity results in an increase in the elastic modulus and tensile/compressive strength of the PEEK [9]. Approximately 40\% increase in tensile strength and $30 \%$ increase in tensile modulus were found in [9] as the crytallity of PEEK 150P increased from $16 \%$ to $39 \%$.

The failure mechanisms of fiber reinforced polymer composites (FRPCs) are rather complex due to their anisotropic material behavior at different scales (micro, meso and macro). There has been several experimental and numerical studies reported in literature to characterize the failure mechanisms of FRPCs under various loading scenarios. In [10], the progressive delamination failure was simulated using a decohesion element coupled with a cohesive zone model $(\mathrm{CZM})$ for $\mathrm{C} / \mathrm{PEEK}$ laminates. The model predictions were compared with dedicated experiments based on DCB, end-notch flexure (ENF) and mixed-mode bending (MMB). The CZM model was used in [11] to simulate the debond strengths of skin-stiffener specimens made of graphite/epoxy loaded in tension and in three-point bending. The stiffness of the specimen, the location of crack initiation and debond loads were found to agree with published experimental data. In [12], the progressive failure analysis was conducted for AS4/PEEK laminates subjected to in-pane tensile and out-of-plane transverse low-velocity impact loading. It was concluded that the proposed elastoplastic damage model resulted in a more accurate predictions of the failure loads for AS4/PEEK $\left[0^{\circ} / 45^{\circ} / 90^{\circ} /-45^{\circ}\right]_{2 s}$ laminates. A CZM was applied to simulate the delamination failure. The CZM was also applied in [13] to simulate the delamination failure mode of a carbon/epoxy pressure vessel. The pin loaded composite laminates were studied in $[14,15]$ using the CZM with dedicated experiments. The delamination onset was determined based on the the specific angle at which the maximum average shear stress occurred at the ply interface in a cross-ply $\left[0^{\circ} / 90^{\circ}\right]_{s}$ laminate in [14]. The failure analysis of T-shaped skin-stiffener composites was particularly studied in [16-21] under pull-off loading and the delamination failure mode was determined experimentally and numerically. In [16] it was shown that the failure initiated in the vertical stiffener due to Mode-I splitting cracks and Mode-I/II pin traction loads controlled the ultimate strength of the T-joint. It was postulated in [19] that the failure mode of a 
T-joint made of T700/bismaleimide resin changed due to the decrease in the fillet/filling ratio and this was yielded in a reduction in the maximum tensile load. The post-damage resistance and energy absorption of a composite T-joints reinforced with through-thickness metallic arrow-pins were significantly increased in [20]. The debonding at the interface between bonded skin-stiffener structure made of graphite/epoxy was simulated in [22] using the virtual crack closure technique (VCCT) [23-26] in ABAQUS. The predicted total strain energy release rate using the shell/3D model was found to agree well with the solid/3D model. Damage mechanisms of a bonded skin-stiffener structure made of glass/epoxy under monotonic tensile load was simulated in [27] using the VCCT and the predicted matrix cracking and delamination were verified with the experiments. It was shown that most of the delaminations took place at the interface of $\left[0^{\circ} / 45^{\circ}\right]$ as well as $\left[90^{\circ} / 45^{\circ}\right]$ layers. In [28], an extented finite element method (XFEM) was simultaneously used with the CZM to simulate the failure behavior of carbon/epoxy samples under open-hole tension loading. The XFEM was utilized to simulate the brittle matrix cracking at the intralaminar level and the CZM was used for predicting the delamination at the interlaminar level. The implemented modelling framework was found to be robust and accurate. The XFEM was also coupled with CZM in [29] to determine the Mode-I failure parameters, i.e. the critical strain energy release rate and the strength of unidirectional carbon/epoxy composite laminate using an experimental-numerical methodology. Only a 2.91\% error was found in the critical strain energy release rate obtained from XFEM and corrected beam theory in [29]. In [30], intralaminar non-linear behaviour and fracture toughness under shear loading of an AS4/PEKK cross-ply composite was investigated. The fracture toughness of the laminate and the matrix was found to be $576.62 \mathrm{~N} / \mathrm{mm}$ and $34.58 \mathrm{~N} / \mathrm{mm}$, respectively.

The fully developed cohesive zone length (CZL) is defined as the distance from the crack tip to the location of the maximum cohesive traction, i.e. irreversible damage onset where the cohesive forces acting on the crack plane [31]. The progressive failure and CZL were studied in [31] for a bonded laminated DCB specimen and it was found that the small cohesive stiffness was the cause for a very small CZL obtained numerically, as compared to 
the theoretically obtained CZL. Recent studies [32, 33] showed that a fine discretization is needed to accurately capture the stress distribution and energy dissipation at the cohesive surfaces. It was shown in [32] that minimum of two or three elements need to be present at the numerical cohesive zone for an accurate load displacement analysis under Mode-I. On the other hand, more than 3 elements, i.e. approximately 3, 5 and 8 elements, used at the cohesive zone for Mode-II gave accurate results in [32] because the CZL in Mode-II load case (in-plane shear mode) is in general larger than the CZL in Mode-I (opening mode). This is due to the fact that the CZL depends on the material properties such as elastic modulus, fracture toughness and interface strength of the cohesive layer and usually the fracture toughness and interface strength are higher in Mode-II than in Mode-I. The CZL for Mode-I $\left(L_{C Z L, I}\right)$ and Mode-II $\left(L_{C Z L, I I}\right)$ are estimated using the following formulas which are based on an approximation of the CZL in slender beams [33, 34]:

$$
\begin{gathered}
L_{C Z L, I}=M_{I} \frac{G_{I c} E_{I}}{\tau_{I c}^{r}} \\
L_{C Z L, I I}=M_{I I} \frac{G_{I I c} E_{I I}}{\tau_{I I c}^{r}}
\end{gathered}
$$

where $E_{i c}, G_{i c}, \tau_{i c}, M_{i}$ and $r=2$ are the equivalent elastic modulus, the critical energy release rate, the interface strength, the dimensionless constant and the exponent constant, respectively. In a recent study [35], $r$ was found to be between 0.8 and 0.9 for a relatively softer ballistic composite (Dyneema HB26) with thick bending arms under Mode-I.

Although there has been several studies carried out to analyze and simulate the mechanical performance of composite structures, a critical assessment of the failure behavior and CZL in hybrid butt jointed TPCs needs to be addressed to develop future's high damage tolerant composites. In this paper, the failure and fracture behavior of a recently developed co-consolidated hybrid C/PEKK skin-stiffener structure was investigated experimentally and numerically. The laminated skin and web made of AS4/PEKK prepregs were co-consolidated together with an injection molded butt joint (filler) made of short fiber reinforced AS4/PEKK. Two different layup sequences were considered. The mechanical response 
of the hybrid structure was evaluated under three point bending (3PB) loading. The crack initiation and propagation in the filler as well as delamination initiation and progression at the skin-filler interface were captured using a high speed camera. A quasi-static model was developed to predict the force-displacement response and the fracture behavior using the finite element method (FEM). The CZM was employed simultaneously with the XFEM in ABAQUS. The evolution of the CZL at the filler-skin interface was critically assessed during loading. In addition, the effect of interface strength and critical strain energy release rate on the CZL were evaluated. The material properties needed for the FEM were characterized experimentally for the filler. The thermal residual stresses were also taken into consideration.

\section{Experimental}

\subsection{Materials}

The laminated skin and web were made of unidirectional (UD) AS4/PEKK prepregs from Cytec. The butt joint, i.e. the filler, was the injection molded 20\% short AS4 carbon filled PEKK. The laminated skin and web were co-consolidated in an autoclave tooling together with the filler to have the T-shaped joint structure. Two different layups were used for the skin and web using the UD prepregs with 16 layers to investigate the influence of layup orientation at the skin-filler interface on the fracture behavior and global force drop after fracture:

- Layup-1 : [0/45/-45/90/45/0/-45/90]s

- Layup-2 : [45/0/-45/90/45/0/-45/90]s

The skin-stiffener specimens were cut from a relatively large panel into small pieces using a diamond saw and prepared with a nominal width of $14.9 \mathrm{~mm}$ and a nominal length of 70 $\mathrm{mm}$ with a span length of $57 \mathrm{~mm}$. The micrograph of a Layup-2 cross-section is depicted in Fig. 1. 


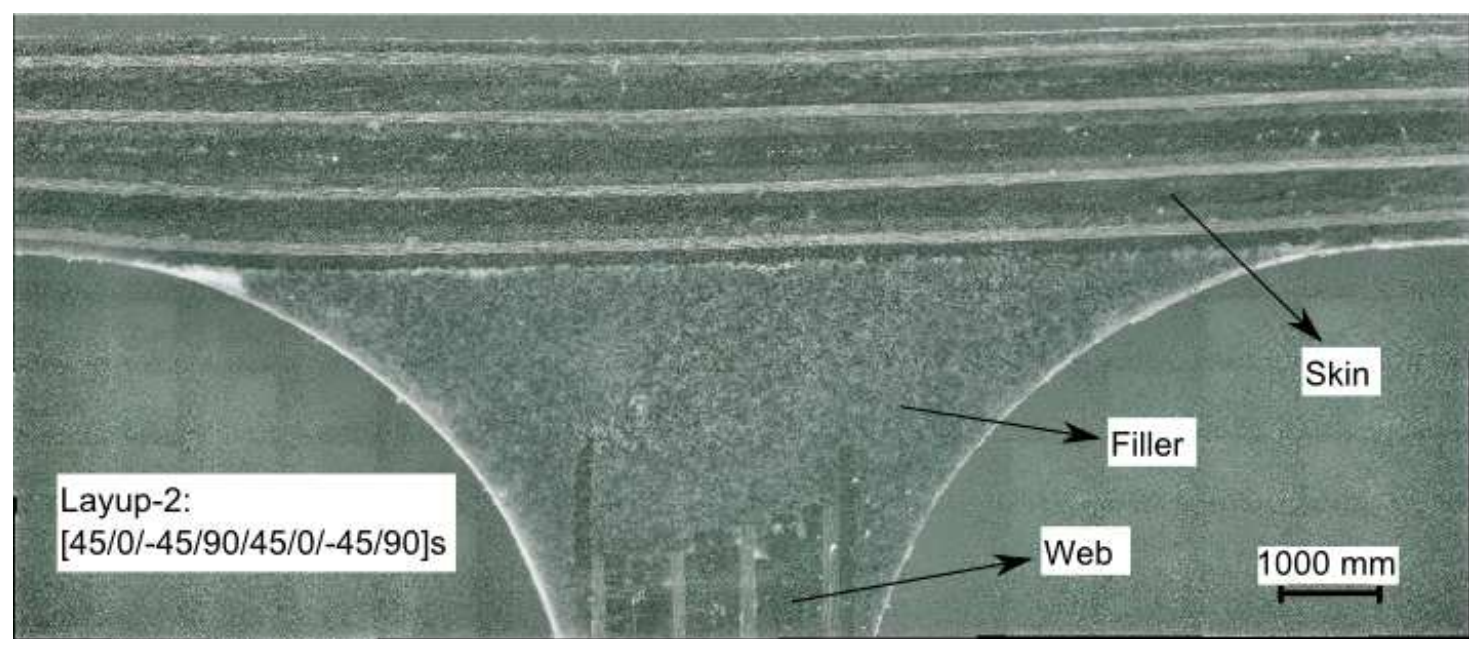

Figure 1: Micrograph of the cross section of a Layup-2 specimen.

\subsection{Material characterization of the filler}

\subsubsection{Tensile properties}

The behaviour of the butt-jointed skin-stiffener specimen is largely dictated by the filler material. In particular the properties transverse to the fibers are important for the 3PB studied in this paper. The linear elastic properties of the filler were measured for the $20 \%$ filled C/PEKK injection molded dog-bone specimens (total of 6) using Zwick Z100 tensile machine at room temperature. Instron clip-on extensometers were attached to the specimen to measure the mechanical strains in the in-plane directions in order to estimate the mechanical properties. Fig. 2(a) shows the corresponding setup. Such specimens had the most short carbon fibres oriented in the longitudinal direction of the dog-bone specimens, therefore the tensile properties were obtained for the longitudinal direction according to ISO527-2 [36]. The stiffness was evaluated using the stress-strain data which showed a linear relation without sign of extensive plasticity in the vicinity of the fracture zone. Detailed results are presented in Table 1 obtained from dog-bone specimens. In Table $1, E$ is the elastic modulus, $\nu$ is the Poisson's ratio and $X^{\text {tensile }}$ is the tensile strength. 


\subsubsection{Flexural properties}

Due to lack of dog-bone specimens prepared in the transverse direction, the properties in the transverse direction were obtained using short beam specimens cut from injection moulded dog-bone specimens in the injection direction (1) and transverse direction (2) as seen in Fig. 2(b,c). Total of 6 specimens from each types were cut with a diamond saw. Due to the limited width of the dog-bones, the length of the specimens was limited to $25 \mathrm{~mm}$. The span length of the 3PB set-up was $19.7 \mathrm{~mm}$ and the nominal thickness of the specimens was $3.5 \mathrm{~mm}$. The measurements were performed in two steps, starting with modulus measurements at lower load values, following with a fracture test. The modulus was determined after 3 runs, in order to have the specimen set in the set-up. Results showed that there was hardly any stiffness difference between the second and third run. The modulus was determined between forces of $150 \mathrm{~N}$ and $250 \mathrm{~N}$, from a force where the force-displacement showed a linear relation. Due to the relatively short span length compared to the thickness, the influence of shear deflection was also taken into account for evaluating the elasticity modulus. The standard elasticity modulus evaluation reads for a 3PB loading [37]:

$$
E_{c}=\frac{L^{3}}{48 C_{c} I}
$$

where $E_{c}$ is the elasticity modulus corrected for the set-up compliance, $L$ is the span length, $C_{c}$ is the measured compliance corrected for the set-up compliance, and $I$ is the second moment of inertia of the beam. Taking the shear deflection into account, $C_{c}$ due to bending can be expressed as [37]:

$$
C_{c}=\frac{L^{3}}{48 E_{c s} I}+\frac{L}{4 k A G}
$$

where $k$ is the shear coefficient which is $5 / 6$ for rectangular cross-sections [38] and $E_{c s}$ is the elasticity modulus corrected for set-up compliance which can be written as:

$$
E_{c s}=\frac{10 G A L^{3}}{48 I\left(10 G A C_{c}-3 L\right)}
$$

where $G$ is the through thickness shear modulus which is estimated as $4 \mathrm{GPa}$ in the present study by considering the transverse shear modulus of a unidirectional ply which is usually in 
the order of magnitude of $4 \mathrm{GPa}$ as also shown in Table 2.. The maximum stress at fracture is calculated as:

$$
X_{T}^{\text {flexural }}=\frac{F_{\max } L h}{8 I}
$$

where $X_{T}^{\text {flexural }}$ is the bending stress at fracture of the filler, $F_{\max }$ is the force at fracture and $h$ is the thickness of the beam. Though no high speed recording has been performed in this case, it is assumed that the crack initiates on the tensile side of the beam and leads to the total fracture of the specimen. The results obtained from short beam bending tests are shown in Table 1 . In table $1, X^{\text {flexural }}$ is the flexural strength. It is assumed that the mechanical properties in the two transverse directions, i.e. 2- and 3-directions, are identical for the filler. The fiber orientation at a $2 \times 3.7 \mathrm{~mm}$ cross section of the $20 \%$ short AS4 carbon filled PEKK was checked using an optical microscopy (Keyence VHX-5000 with the VH-Z100UR/W/T lens) and the results are shown in Fig. 3. It is seen that the fibers are highly oriented in the injection direction, i.e. 1-direction.
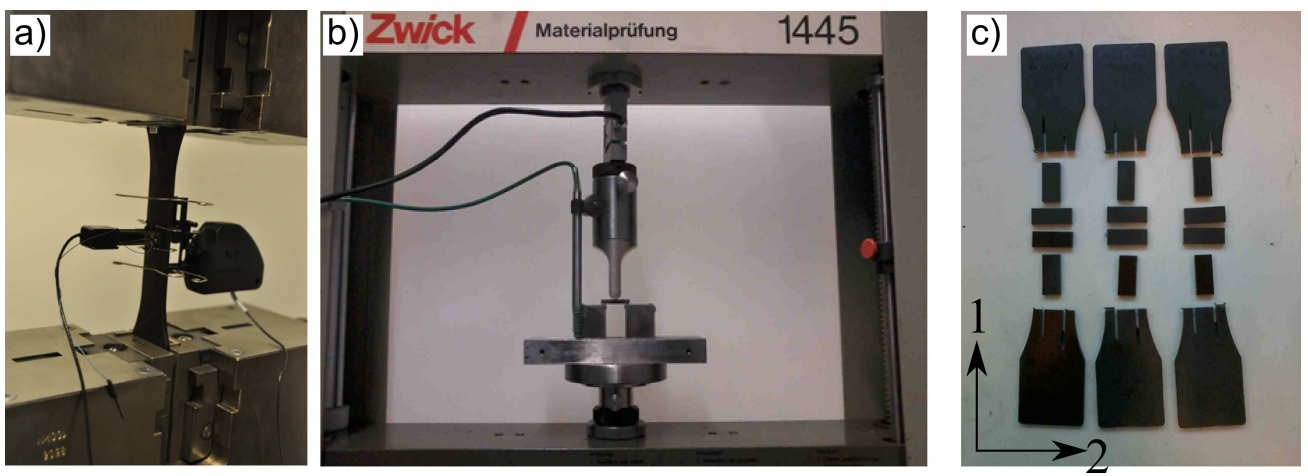

Figure 2: a) Set-up used for the measurement of tensile properties of the filler. b) Set-up used for the measurement of bending properties of the filler. c) Short beam specimens for longitudinal and transverse properties. Fibers are oriented in the 1-direction.

\subsubsection{Coefficient of thermal expansion (CTE)}

The CTEs in the injection and transverse to the injection direction were measured using a Mettler Thermo Mechanical Analyzer (TMA). A TMA measures dimensional changes of a specimen as a function of temperature, using a well-controlled temperature chamber and a 


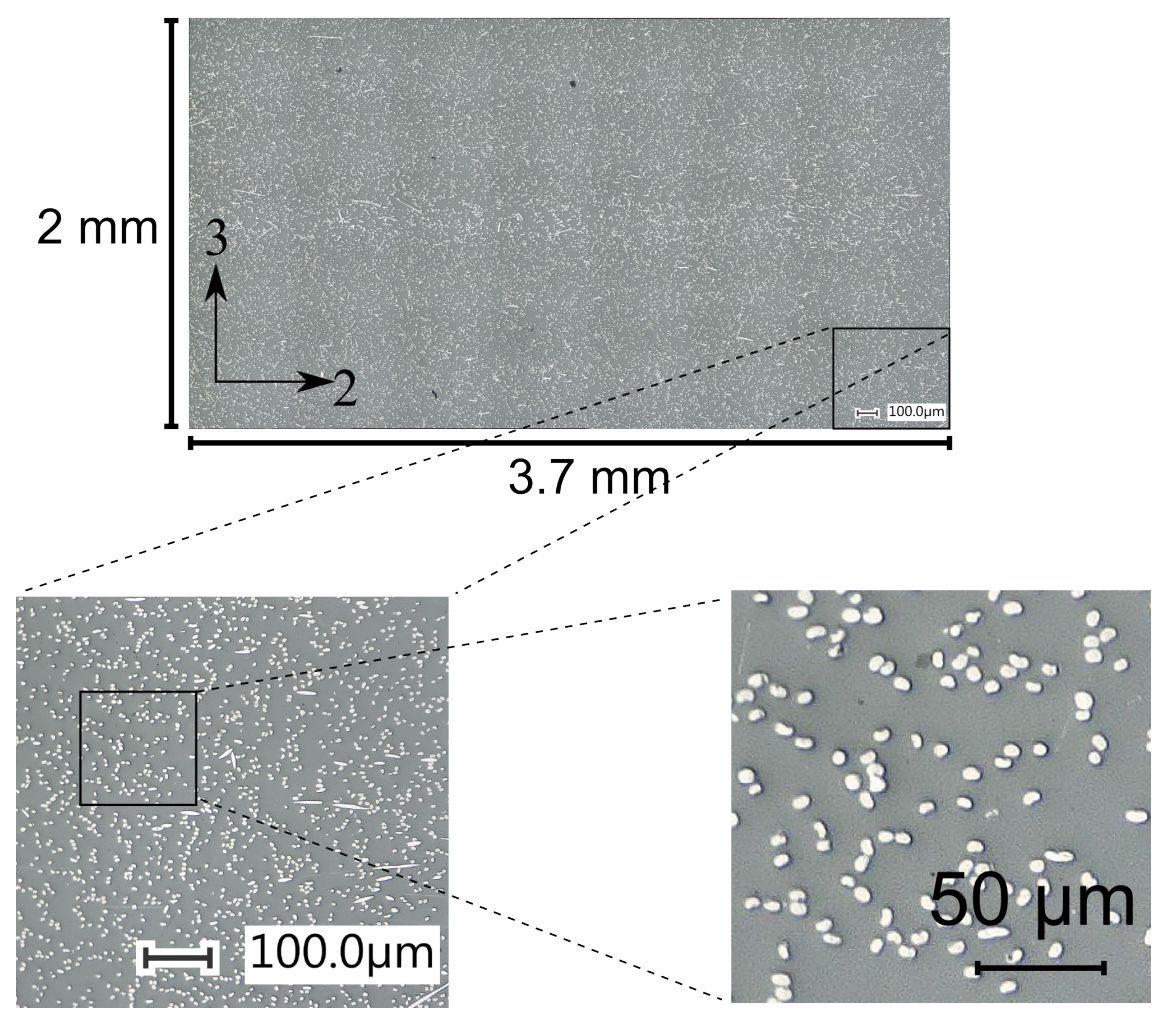

Figure 3: Micrograph showing the fiber distribution of injection molded 20\% short AS4 carbon filled PEKK on the transverse plane. Fibers are mainly oriented in the 1-direction.

LVDT (Linear Variable Displacement transducer) to measure the dimension change. Total of 4 specimens in the longitudinal and transverse direction were cut from injection molded specimens as for the bending tests. Nominal length was $8 \mathrm{~mm}$, with a thickness of $3.4 \mathrm{~mm}$, and a width between 3 and $4 \mathrm{~mm}$. Most tests were performed at a rate of $1 \mathrm{~K} / \mathrm{min}$ to start with, and later at $4 \mathrm{~K} / \mathrm{min}$, in a range between $30^{\circ} \mathrm{C}$ and $120^{\circ} \mathrm{C}$. The TMA tests of a single specimen at these two rates did not give any significant difference. The obtained CTEs are listed in Table 1 in the longitudinal and transverse directions, i.e. $\alpha_{1}$ and $\alpha_{2}$, respectively.

\subsection{Mechanical testing}

The mechanical response of the hybrid butt jointed composite was observed under 3PB test conditions. The $3 \mathrm{~PB}$ was selected because it is easy to apply and allows an impact test application under non quasi-static conditions. The side surfaces of each specimens were then manually grinded in water. A local curvature in the skin and neighborhood of the filler was 
Table 1: Material properties of $20 \%$ filled C/PEKK injection molded filler obtained from tensile, bending and TMA tests. Note that 1 is the longitudinal (injection) direction, 2 and 3 are the directions transverse to the fiber direction.

\begin{tabular}{llll}
\hline & Mean & Standard deviation (\%) & Test \\
\hline$E_{1}[\mathrm{GPa}]$ & 16.2 & 1.5 & Dog-bone tensile \\
$E_{1}[\mathrm{GPa}]$ & 16.4 & 4.5 & Short beam bending \\
$E_{2}=E_{3}[\mathrm{GPa}]$ & 6.1 & 1.0 & Short beam bending \\
$\nu_{12}=\nu_{13}$ & 0.42 & 14 & Dog-bone tensile \\
$X_{1}^{\text {tensile }}[\mathrm{MPa}]$ & 192.0 & 0.3 & Dog-bone tensile \\
$X_{1}^{\text {flexural }}[\mathrm{MPa}]$ & 308.0 & 1.3 & Short beam bending \\
$X_{2}^{\text {flexural }}[\mathrm{MPa}]$ & 191.0 & 1.3 & Short beam bending \\
$\alpha_{1}[\mathrm{ppm} / \mathrm{K}]$ & 9.3 & 1.1 & TMA \\
$\alpha_{2}[\mathrm{ppm} / \mathrm{K}]$ & 43.2 & 2.1 & TMA \\
\hline
\end{tabular}

observed due to the process induced residual thermal and shrinkage stresses $[39,40]$. Because of that, the thickness of the skin was also found to be varying throughout the stiffened panel. In this work, three specimens taken from different places along the butt jointed panel were presented. The nominal thickness of the specimens was $2.32 \mathrm{~mm}$ and the nominal radius of the filler was $6 \mathrm{~mm}$. The quasi-static 3PB tests were carried out using a $10 \mathrm{kN}$ capacity Zwick uniaxial tensile system with a loading rate of $1 \mathrm{~mm} / \mathrm{min}$ and a $1 \mathrm{kN}$ Zwick force cell. A photo of the $3 \mathrm{~PB}$ setup is shown in Fig. 4. The nominal roller diameters were $10 \mathrm{~mm}$. The initiation and growth of the crack as well the post delamination behavior was captured using a high speed camera (Photron Fastcam SA4 with 30000 frames per second) during the 3PB tests. For this purpose, the camera was focused on the full width of the filler, in the region of its interaction with the skin.

\section{FEM Model}

The 3PB test was simulated using a two-dimensional (2D) quasi-static analysis in ABAQUS since the width of the specimen is relatively small as compared with the cross sectional di- 


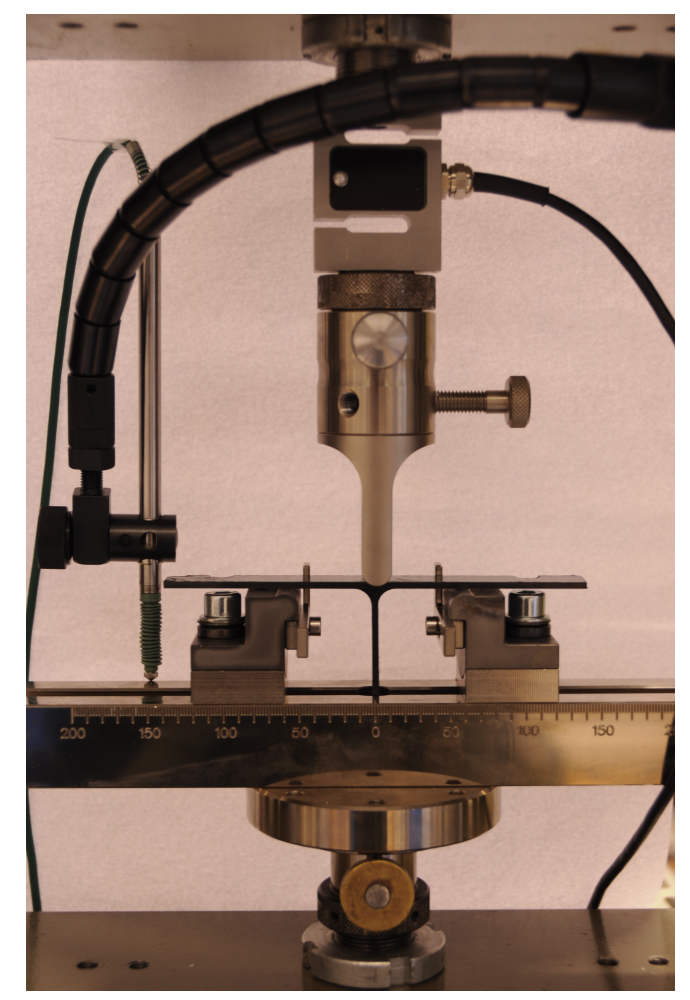

Figure 4: The 3PB setup of T-joints.

mensions. A schematic view of the model with the enmeshment is depicted in Fig. 5. A total of 115024 node bilinear quadrilateral plane strain elements (CPE4) available in ABAQUS are used as in [33]. The web was connected to the filler using the tie constraint interface contact defined in ABAQUS. A cohesive surface was defined at the skin-filler interface using a traction separation law to simulate the delamination and predict the CZL. The element size at the cohesive surface was determined as $0.1 \mathrm{~mm}$ based on a mesh sensitivity analysis from which stable and converged results were obtained as compared with the measurements. The VCCT was implemented to predict the crack initiation and growth in the filler. Since the crack initiated only from one curved part of the filler according to the experiments, only half of the filler domain was included in the VCCT as seen in Fig. 5 (right). The support and loading pins were modelled using rigid analytic surfaces since the pins had much higher stiffness than the composite and the pin deformations were neglected. A mechanical contact formulation was defined at the pin-skin and support-skin interface which allowed any sliding 
and restricted any penetration of the skin beyond the rigid surfaces.

For Layup-1 and Layup-2, the fiber direction of the $0^{\circ}$ ply was oriented in the global $x$-direction for the skin and in $y$-direction for the web. The aligned short fibers were oriented in the $z$-direction. Two different loading steps were used in the numerical simulations. In the first step, a thermal load was introduced to the hybrid composite structure by applying a temperature gradient $\Delta T$ and the thermal residual stresses were calculated. In the second load step, a displacement $(d)$ was applied at the reference point (RP) seen in Fig. 5 (left) in the negative $y$-direction. The details of the considered values for $\Delta T$ and $d$ together with the material properties are provided in Section 3.3.

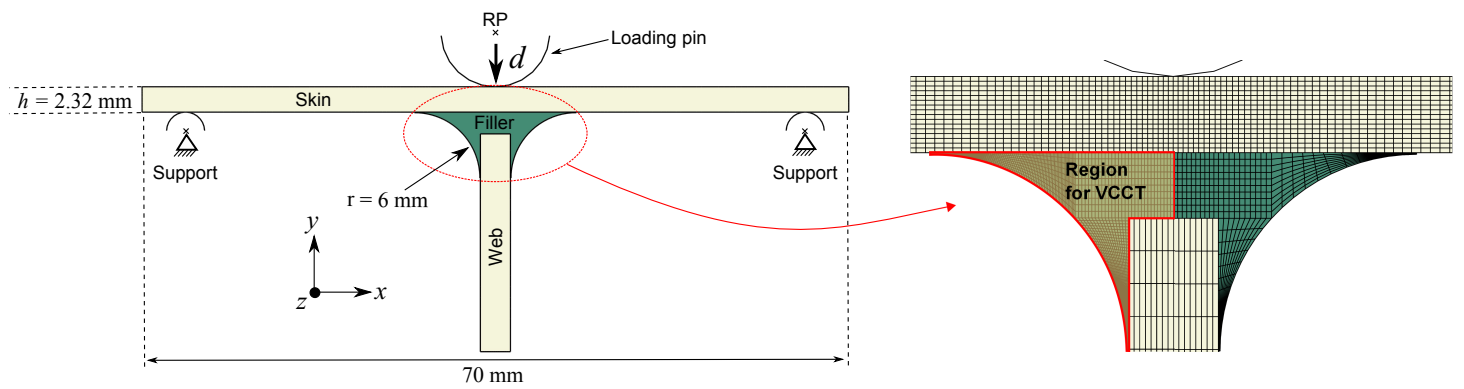

Figure 5: Schematic view of the geometry in the numerical model (left). The details of the enmeshment and region for the VCCT shown with shaded area (right).

\subsection{Delamination at the skin-filler interface}

An uncoupled linear elastic traction separation law was utilized in ABAQUS to simulate the damage initiation and evolution for the cohesive surface. The model is based on the numerical modelling of the mixed-mode progressive delamination proposed in $[10,11]$. The normal and shear stresses are related with the normal and shear separations across the cohesive interface, i.e. skin-filler interface. The uncoupled elastic behavior can be written as:

$$
\mathbf{t}=\left\{\begin{array}{c}
t_{n} \\
t_{s} \\
t_{t}
\end{array}\right\}=\left[\begin{array}{ccc}
K_{n n} & 0 & 0 \\
0 & K_{s s} & 0 \\
0 & 0 & K_{t t}
\end{array}\right]\left\{\begin{array}{c}
\delta_{n} \\
\delta_{s} \\
\delta_{t}
\end{array}\right\}
$$


where $\mathbf{t}$ is the nominal traction stress vector consisting of three components $t_{n}$ (in the normal direction to the cohesive surface), $t_{s}$ (in the first shear direction) and $t_{t}$ (in the second shear direction). The corresponding separations at the interface are denoted by $\delta_{n}, \delta_{s}$ and $\delta_{t}$. It is seen in Eq. 7 that the contact stiffness components $\left(K_{n n}, K_{s s}\right.$ and $\left.K_{t t}\right)$ are not coupled, i.e. pure normal or tangential separations will not contribute to the cohesive forces in the other directions. The damage initiation, which is the beginning of the degradation of the cohesive surface, was defined based on the linear elastic relation in Eq. 7. The process of degradation begins when the contact stresses and/or contact separations satisfy certain damage initiation criteria. For this, a quadratic stress criterion was considered as described in Eq. 8.

$$
\left(\frac{t_{n}}{t_{n}^{\circ}}\right)^{2}+\left(\frac{t_{s}}{t_{s}^{\circ}}\right)^{2}+\left(\frac{t_{t}}{t_{t}^{\circ}}\right)^{2}=1
$$

where $t_{n}^{\circ}, t_{s}^{\circ}$ and $t_{t}^{\circ}$ are the interface strength. It should be noted that $t_{n}$ must be positive (in tension) in order to initiate the delamination at the interface. A linear degradation was used for the damage evolution in which the Benzeggagh-Kenane (BK) fracture criterion [41, 42] was employed to define the mix mode softening of the cohesive surface as seen in Fig. 6 . The corresponding expression is written as:

$$
G_{m c}=G_{I c}+\left(G_{I I c}-G_{I c}\right)\left(\frac{G_{I I}+G_{I I I}}{G_{I}+G_{I I}+G_{I I I}}\right)^{\eta}
$$

where $G_{m c}$ is the critical energy release rate of the mix mode behavior, $G_{I c}, G_{I I c}$ and $G_{I I I c}$ are the critical energy release rate of Mode-I, Mode-II and Mode-III, respectively, $\eta$ is the cohesive property parameter and $G_{I}, G_{I I}$ and $G_{I I I}$ are the energy release rates of Mode-I, Mode-II and Mode-III, respectively. A schematic representation of the mix mode damage evolution is depicted in Fig. 6(right) where $G_{m c}$ can be written as:

$$
G_{m c}=\frac{t_{m}^{\circ} \delta_{m}^{f}}{2}
$$

where $t_{m}^{\circ}$ is the peak value of the mix mode contact stress and $\delta_{m}^{f}$ is the corresponding effective complete separation [42]. The linear degradation of the stiffness is shown in Fig. $6(r i g h t)$. If there is an unloading subsequent to damage initiation, it occurs linearly towards 
the origin of the traction-separation plane. Reloading subsequent to unloading also occurs along the same linear path until the softening envelope (line AB in Fig. 6(right)) is reached.

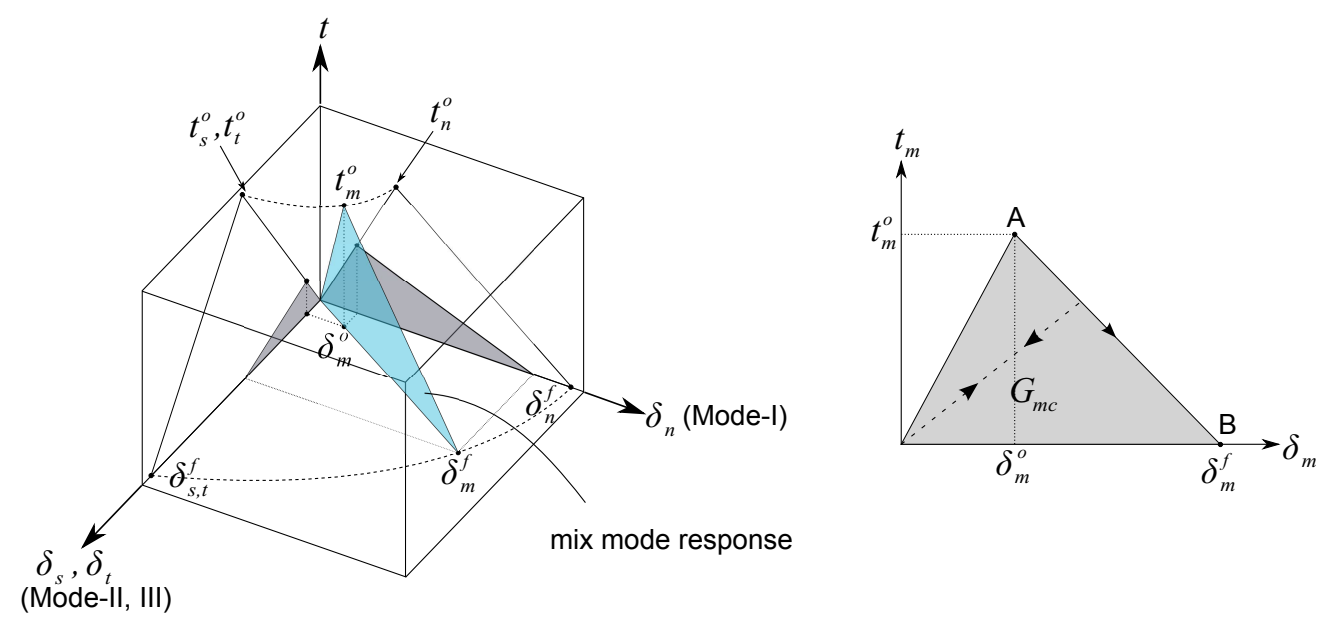

Figure 6: Mix mode damage evolution (left) and the linear softening law (right).

\subsection{Crack initiation and propagation in the filler}

The XFEM-based cohesive zone approach was employed to simulate the arbitrary crack initiation and propagation in the filler, since the crack propagation was not tied to the element boundaries in the mesh. The VCCT uses the principles of linear elastic fracture mechanics (LEFM) and hence is convenient for applications in which brittle crack propagation takes place. This choice was partly supported by the fact that the filler failed in a brittle way in the butt joint structure during the 3PB tests, without significant sign of plastic behavior. The crack initiation was defined using the maximum principal stress criterion for the filler material in ABAQUS. Once the principle stress value is equal or higher than the critical principal stress $\left(\sigma_{\max P}\right)$, than a damage is initiated.

The VCCT is based on the assumption that the strain energy released, when a crack is extended by a certain amount, is the same as the energy required to close the crack by the same amount $[23,24]$. For instance, the energy released when the crack is extended by $\Delta x$ from $x$ to $x+\Delta x$ as seen in Fig. 7 is identical to the energy required to close the crack between location $i$ and $i *$ (closure of element $E 1$ and element $E 2$ in Fig. 7). Fig. 7 shows a 
$3 \mathrm{D}$ crack model in which the $z$-direction is in the out-of-plane direction and the model has a thickness of $\Delta z$ in the $z$-direction. The total work required to close the crack along one element, i.e. the crack between element $E 1$ and element $E 2$, can be written as:

$$
\Delta E=\frac{1}{2}\left[F_{y, j}\left(v_{i}-v_{i *}\right)+F_{x, j}\left(u_{i}-u_{i *}\right)+F_{z, j}\left(w_{i}-w_{i *}\right)\right]
$$

where $F_{x, j}, F_{y, j}$ and $F_{z, j}$ are the forces acting on node $j$ in the $x$-, $y$ - and $z$-direction, respectively, $u_{i}, v_{i}$ and $w_{i}$ are the displacements at node $i$ and similarly $u_{i *}, v_{i *}$ and $w_{i *}$ are the displacements at node $i *$ in the $x$-, $y$ - and $z$-direction, respectively. The strain energy release rate $G$ can be defined as the ratio between the total work $(\Delta E)$ and the crack surface $(\Delta x \Delta z)$. The components of the strain energy release rate $\left(G_{I}, G_{I I}\right.$ and $\left.G_{I I I}\right)$ for Mode-I, Mode-II and Mode-III can be calculated as [26]:

$$
\begin{aligned}
G_{I} & =\frac{1}{2 \Delta x \Delta z}\left[F_{y, j}\left(v_{i}-v_{i *}\right)\right] \\
G_{I I} & =\frac{1}{2 \Delta x \Delta z}\left[F_{x, j}\left(u_{i}-u_{i *}\right)\right] \\
G_{I I I} & =\frac{1}{2 \Delta x \Delta z}\left[F_{z, j}\left(w_{i}-w_{i *}\right)\right]
\end{aligned}
$$

The BK law defined in Eq. 9 was used for the linear damage evolution in the filler.
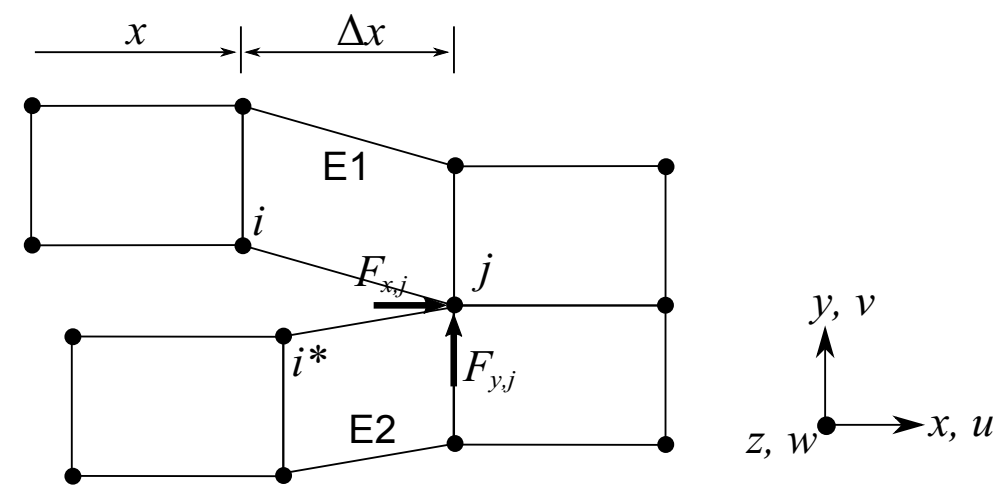

Figure 7: Representation of the virtual crack closure technique (VCCT).

\subsection{Model parameters}

The material properties of the $0^{\circ}$ layer in the skin and web were taken from $[42,43]$ and given in Table 2. Note that the subscript 1 refers the longitudinal direction. 
The parameters used in the traction separation law defined at the cohesive surface between the skin and filler were taken from [42] in which the mix mode cohesive properties were provided for a AS4/PEEK using the BK criterion over a wide range of mode ratio. Since the interface parameters for PEKK composites are still missing in literature for mix mode delamination, the material input for AS4/PEEK in [42] was considered as the mix mode behavior is also the case in the present work. The corresponding values are given in Table 3 . The values for the penalty stiffness $\left(K_{n n}, K_{s s}\right.$ and $K_{t t}$ in Eq. 7$)$ at the cohesive surface were taken as $10^{6} \mathrm{~N} / \mathrm{mm}^{3}$ [42] in order not to affect the overall stiffness of the structure during thermal loading and applied displacement.

Experimentally obtained parameters presented in Table 1 were used for the filler in the numerical model. Since there was only flexural bending strength (see Table 1) data available in the transverse direction and the transverse strength was unknown for the filler, a parametric study was performed based on the damage initiation criteria defined in the filler (see Section 3.2). The values of the critical maximum principle stress $\sigma_{\max P}$ used in the parametric analysis were determined by considering the following facts:

- the tensile strength of pure PEKK is $102 \mathrm{MPa}$ [44] and according to [45], the transverse tensile strength of short fiber reinforced PA6 was found to be approximately $50 \%$ higher than the tensile strength of pure PA6.

- the tensile strength is generally lower than the flexural strength $\left(X_{2}^{\text {flexural }}=191 \mathrm{MPa}\right)$. Hence, $\sigma_{\max P}$ of the filler was varied from $120 \mathrm{MPa}$ to $160 \mathrm{MPa}$ with $10 \mathrm{MPa}$ increments in the FEM model. The same fracture energy values listed in Table 3 were used for the damage evolution in the filler.

As aforementioned, a thermal load was imposed by applying a temperature gradient $(\Delta \mathrm{T})$ to the butt jointed composite. Since the PEKK is a semi-crystalline thermoplastic, there is hardly residual stresses built up until the stress free temperature which is the crystallization peak temperature $[39,46,47]$. The crystalline phases have the load bearing capability below 
crystallization peak temperature and the residual stresses can be built up during cooling due to the mismatch in the thermal shrinkage behavior between the matrix and the fiber reinforcement. However, the elastic modulus exhibits a sharp drop in the vicinity of the glass transition temperature [48]. Therefore, significant portion of the residual stresses are built up between just above the glass transition temperature and the room temperature (20 $\left.{ }^{\circ} \mathrm{C}\right)[49]$ which is also considered in the present study. According to the manufacturers data sheet of PEKK [44], the melting point is $337{ }^{\circ} \mathrm{C}$, glass transition temperature is $159{ }^{\circ} \mathrm{C}$ and crystallization temperature is $279{ }^{\circ} \mathrm{C}$. Hence, $\Delta T$ was taken as $20-159=-139{ }^{\circ} \mathrm{C}$ in the thermal loading simulation.

Table 2: Material properties of a UD AS4/PEKK layer [42, 43].

\begin{tabular}{llllllll}
$E_{1}[\mathrm{GPa}]$ & $E_{2}=E_{3}[\mathrm{MPa}]$ & $\nu_{12}=\nu_{13}$ & $\nu_{23}$ & $G_{12}=G_{13}[\mathrm{GPa}]$ & $G_{23}[\mathrm{GPa}]$ & $\alpha_{1}[\mathrm{ppm} / \mathrm{K}]$ & $\alpha_{2}[\mathrm{ppm} / \mathrm{K}]$ \\
\hline 139 & 10.3 & 0.3 & 0.45 & 5.2 & 3.7 & 9.3 & 43.2 \\
\hline
\end{tabular}

Table 3: Parameters used in the traction separation law for the cohesive surface between filler and skin [42].

\begin{tabular}{lllll}
\hline$G_{I c}[\mathrm{~N} / \mathrm{mm}]$ & $G_{I I c}=G_{I I I c}[\mathrm{~N} / \mathrm{mm}]$ & $\eta$ & $t_{n}^{\circ}[\mathrm{MPa}]$ & $t_{s}^{\circ}=t_{t}^{\circ}[\mathrm{MPa}]$ \\
\hline 0.969 & 1.719 & 2.284 & 80 & 100 \\
\hline
\end{tabular}

\section{Results and discussion}

\subsection{Failure behavior}

The pictures taken by the high speed camera are depicted in Fig. 8 which show the crack initiation and propagation during $3 \mathrm{~PB}$. The sample rate was $33 \mu$ s with a resolution of $640 \times 376$ pixels and the available light was the artificial Cold Halogen. For this purpose, the camera was focused on the full width of the filler, in the region of its interaction with the skin. The fracture initiated in both cases, i.e. Layup-1 and Layup-2, in the filler, a few tenth of millimeters from the filler-skin interface. The crack then grew towards this interface in 
less than $33 \mu \mathrm{s}$. The crack grew further at the filler-skin interface in case of Layup-1, where the fiber orientation of the laminate top layer, parallel to the beam direction, prevented the formation of transverse cracks. In case of the Layup-2 however, post testing micrography (Fig. 9) showed that transverse cracks existed in the top $45^{\circ}$ layer, as well as a delamination between the $45^{\circ}$ and the $0^{\circ}$ layer. The unstable crack growth was also noticed in the force-displacement graph supporting the high speed camera pictures, which show that the butt joint was separated from the main laminate within 1 to $2 \mathrm{~ms}$. The specimens built up in Layup-1 were obviously stiffer than the one built up with Layup-2 due to the inherent higher bending stiff layup chosen in Layup-1. The force at which the filler fractured was also higher for the Layup-1 specimens $(730-760 \mathrm{~N})$ than the Layup-2 (570-650 N). As expected, the displacement at fracture was higher for Layup-2 $(2.52-2.68 \mathrm{~mm})$ than Layup-1 (2.29-2.49 $\mathrm{mm})$. The drop in force resulting from the fracture was sudden and of a large amplitude of approximately in the range of 110-150 N. The variation in the measured force and displacement for three different specimens might be due to the fact that the thickness of the skin slightly differed. The fractured structure was able to carry load with reduced stiffness after unstable fracture which can be seen from Fig. 10. The delamination at the filler-skin interface stopped after the sharp drop in force.

Load-displacement response obtained from the experiments are compared with the ones obtained from numerical simulations in Fig. 10. The numerical findings for the linear elastic behavior agreed well with the experiments for different $\sigma_{\max P}$ values used in the XFEM defined for the damage initiation in the filler. Among 5 different values, $\sigma_{\max P}=140$ and $150 \mathrm{MPa}$ were found to provide closer force and displacement at fracture for Layup-1 and Layup-2 as seen in Fig. 10. The predicted force drop also matched well with the force drop in experiments. The development of the crack in the filler and the delamination at the fillerskin interface obtained from the numerical model are shown in Fig. 11 for Layup-1 with $\sigma_{\max P}=140 \mathrm{MPa}$. The cohesive surface damage (CSDMG) distribution is also shown in Fig. 11. $\mathrm{CSDMG}=0$ refers undamaged material and $\mathrm{CSDMG}=1$ stands for complete failure (no stiffness in the material) for the cohesive surface. The simulations show similar conclusions 

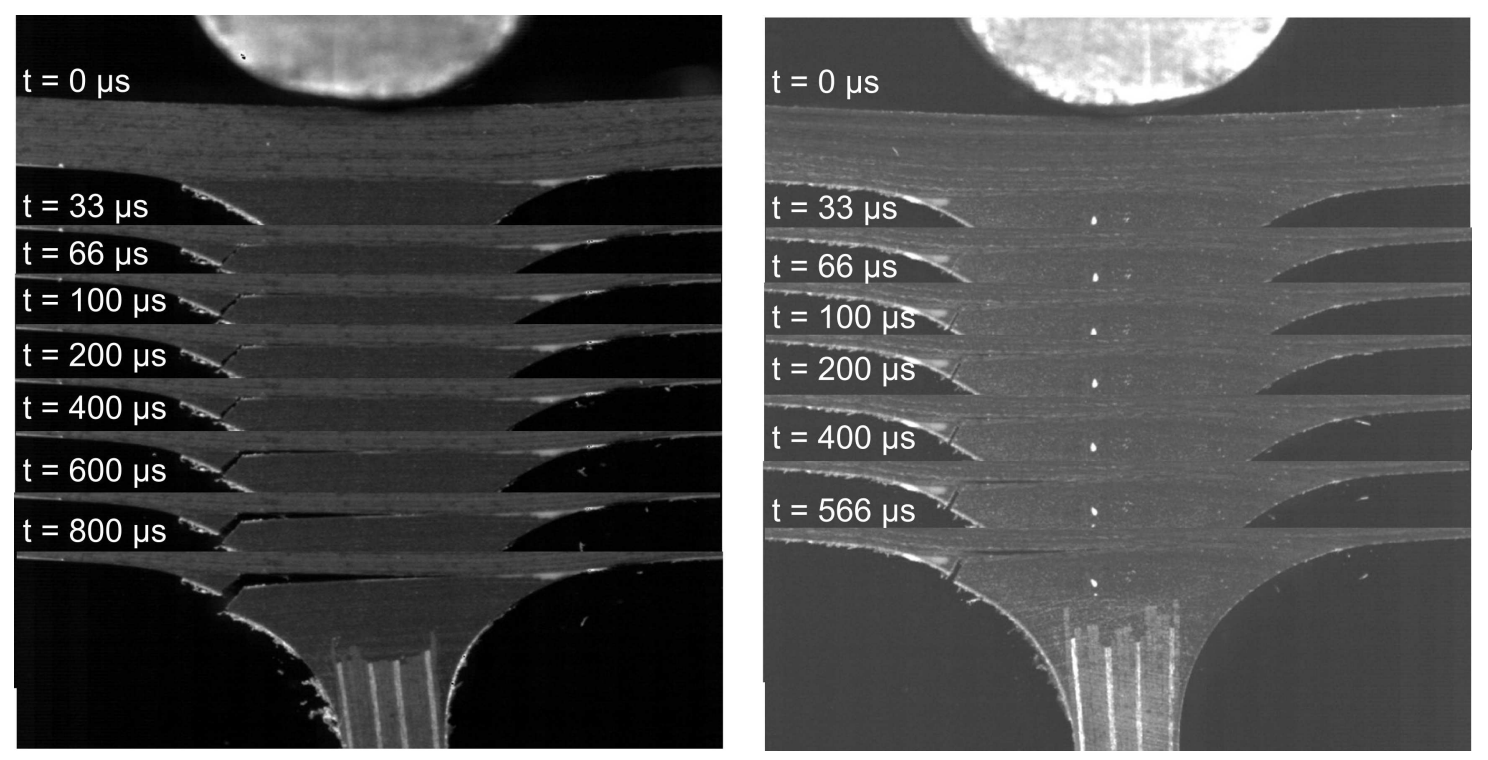

Figure 8: High speed camera shots for Layup-1 specimen (left) and Layup-2 specimen (right) under threepoint bending conditions.

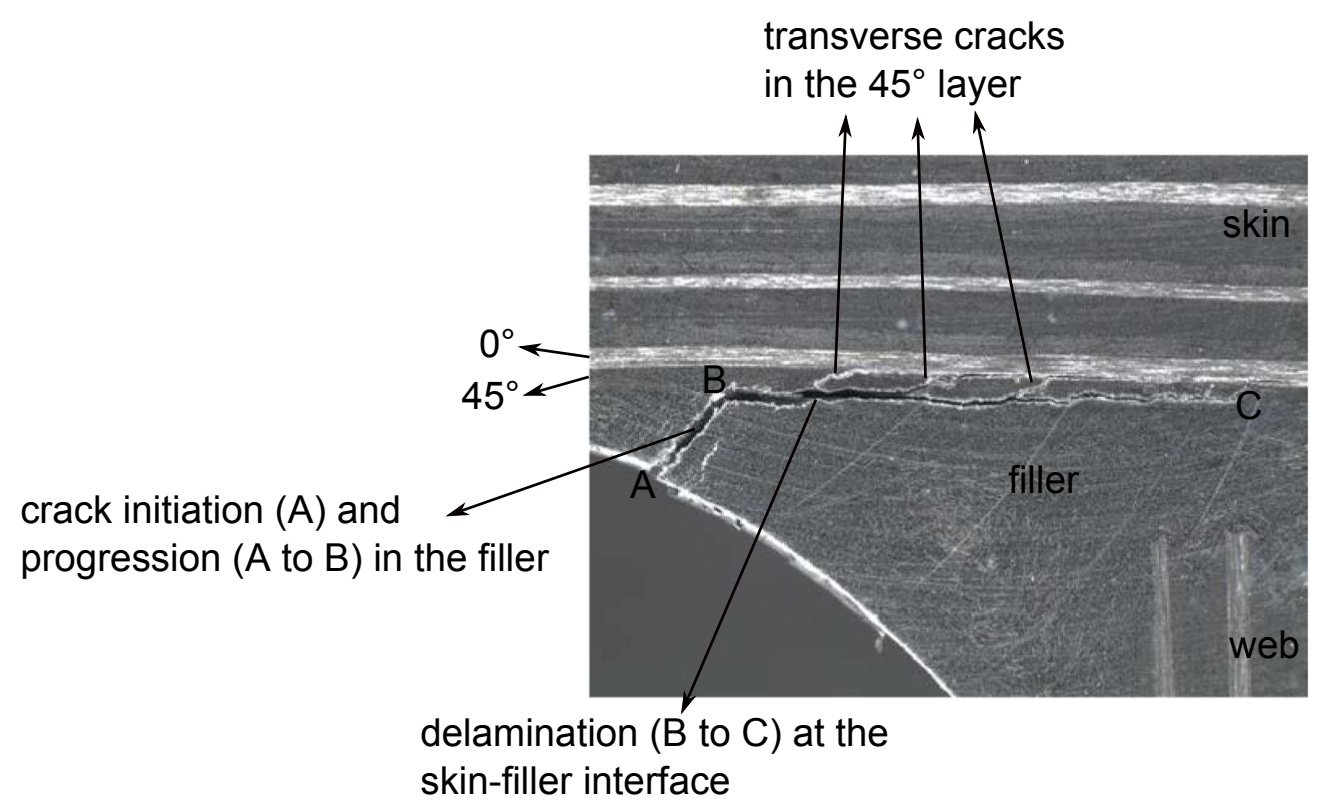

Figure 9: Micrograph of the cracked filler and filler-skin interface for Layup-2 with transverse cracks in the $45^{\circ}$ layer as well as delamination between filler-skin $\left(45^{\circ}\right)$ interface and between $45^{\circ}-0^{\circ}$ layer.

with the experimental observations:

- Crack initiation in the filler (Fig. 11(a)) 
- Crack growth in the filler and initiation of the delamination at the filler-skin interface (Fig. 11(b))

- Delamination growth at the filler-skin interface and ending of the delamination after force drop (Fig. 11(c))
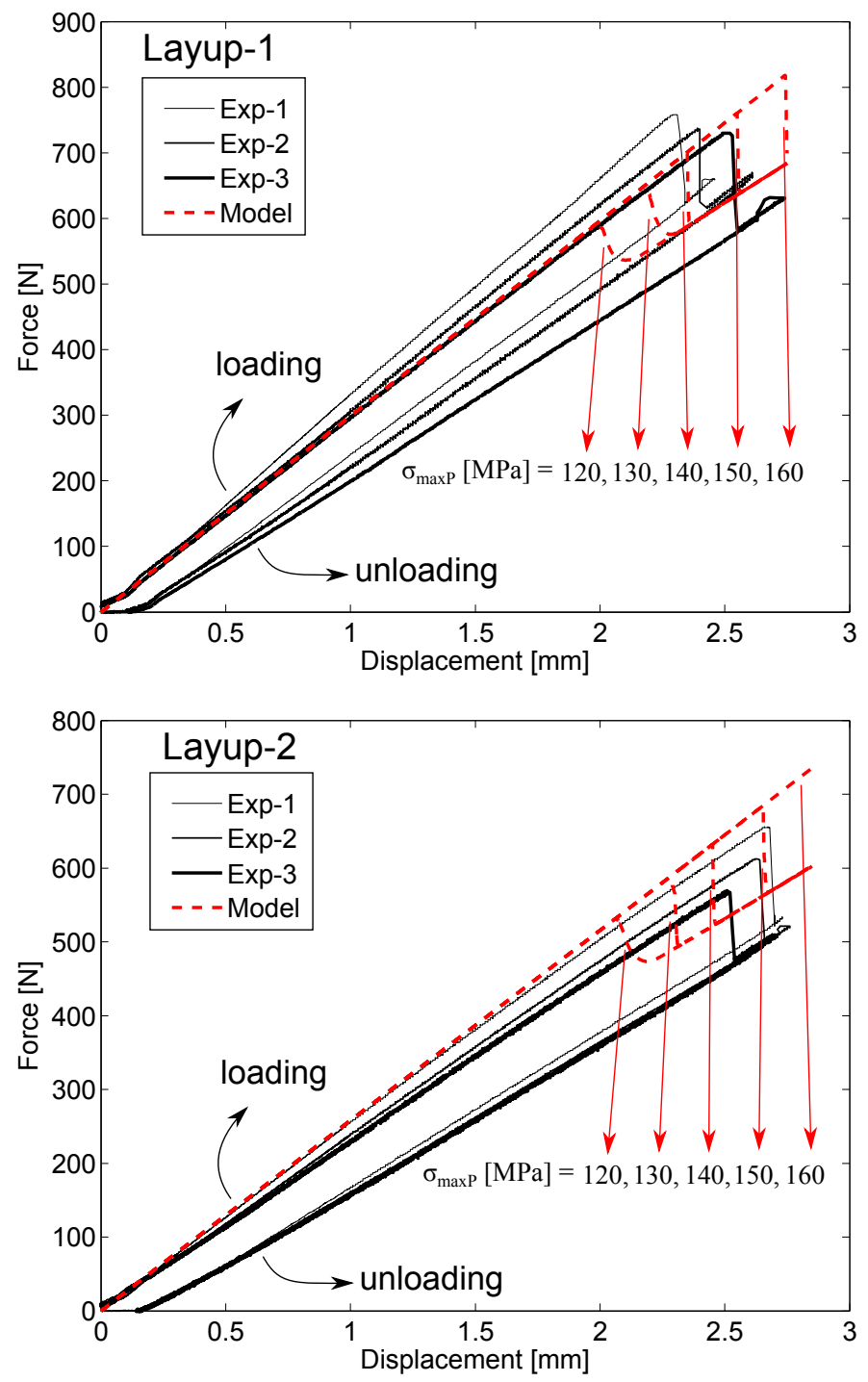

Figure 10: Force-displacement response under 3PB conditions for Layup-1 (top) and Layup-2 (bottom). 


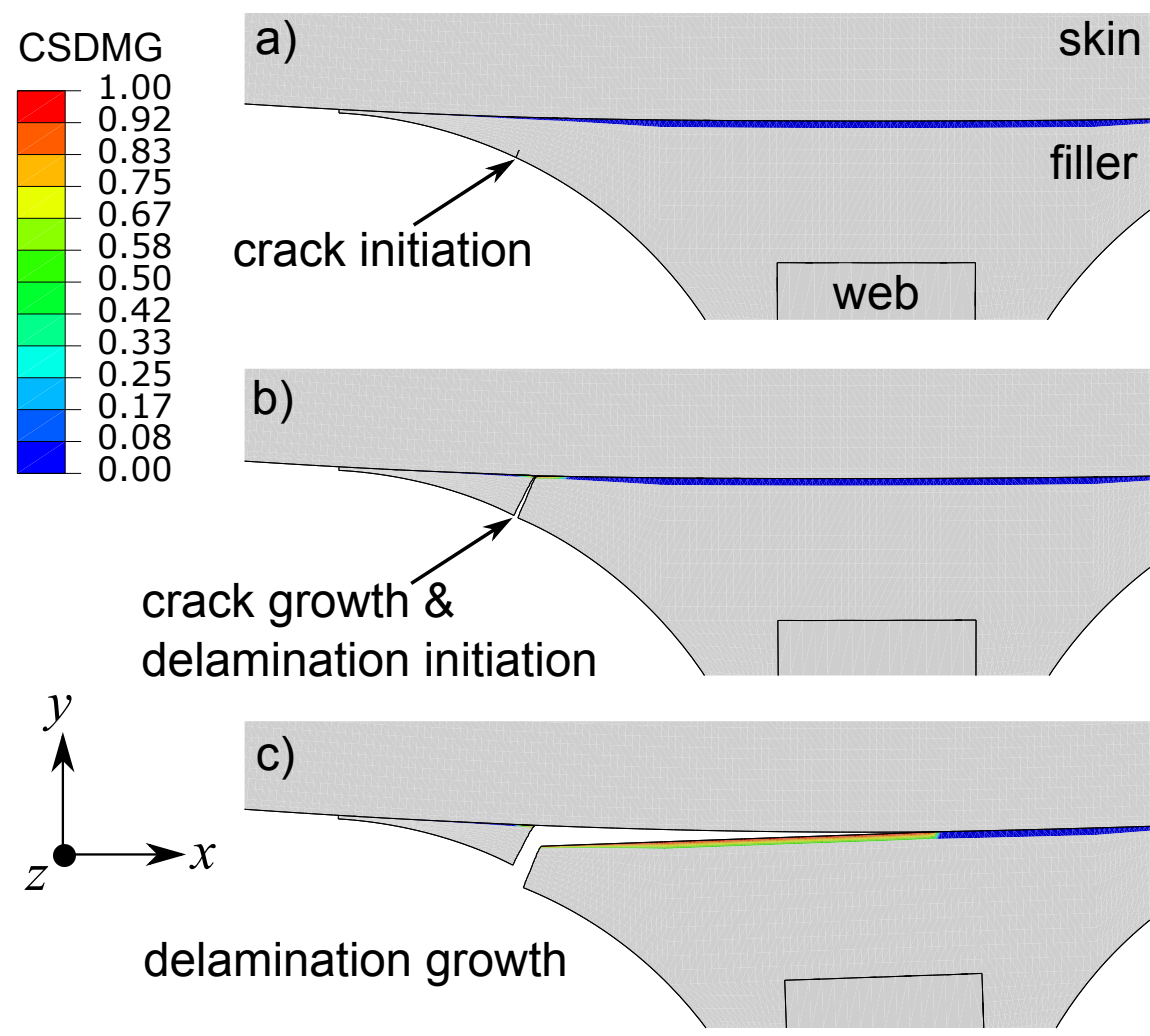

Figure 11: The predicted fracture behavior in the filler and at the skin-filler interface with cohesive surface damage $(\mathrm{CSDMG})$ distribution for Layup-1 $\left(\sigma_{\max P}=140 \mathrm{MPa}\right)$. a) crack initiation in the filler, b) crack growth in the filler and delamination inititation at the filler-skin interface c) propagation of the delamination at the skin-filler interface.

\subsection{Cohesive zone length (CZL)}

It was found that the traction at the cohesive surface varied during the 3PB loading without any damage as well as during the delamination. Note that similar failure behavior was obtained for Layup-1 and Layup-2, therefore results are presented only for Layup-1 in the following. The predicted traction distributions along the filler-skin interface after thermal loading and at the beginning of damage initiation in the filler are shown in Fig. 12. The position at the filler-skin interface, i.e. $x$-direction, is illustrated in Fig. 13 . It is seen from 12 that there was no delamination onset taking place because the interface stresses $\left(t_{n}\right.$ and $\left.t_{s}\right)$ were much lower than the interface strength of the cohesive surface $\left(t_{n}^{\circ}=80 \mathrm{MPa}\right.$, $t_{s}^{\circ}=100 \mathrm{MPa}$ ). Fig. 13 shows schematically how the traction develops ahead of the crack 
tip during delamination at the filler-skin interface. The delamination started at position $x_{i n i}$, the position of the crack tip was defined as $x_{\text {crack }}$ and the location of the maximum traction was $x_{\max }$. The CZL was defined as $x_{\max }-x_{c r a c k} . x_{i n i}$ was found to be approximately $2.45 \mathrm{~mm}$ from the simulations. The normal and shear stresses at the cohesive surface were found to vary during delamination due to the nature of mix mode behavior of the filler-skin interface with respect to the loading. When the delamination started, the traction in the normal direction $\left(t_{n}\right)$ and shear direction $\left(t_{n}\right)$ developed in a way that $t_{n}$ was more dominant than $t_{s}$ at the beginning of delamination. During delamination progression and near the end of delamination where it stopped, $t_{s}$ leaded the main delamination mode. This can be understood from the development of the ratio of maximum traction $\left|t_{n} / t_{s}\right|$ as a function of $x_{\max }$ as illustrated in Fig. 14 . The delamination stopped approximately at $x=7.9 \mathrm{~mm}$. Fig. 14 shows that Mode-I opening was dominant at the delamination initiation and Mode-II in-plane shear became more effective than Mode-I during the growth of delamination and near the delamination end. The predicted CZL evolution during delaminaton growth as a function of $x_{\max }$ is shown in Fig. 15. The CZL increased approximately from $0.45 \mathrm{~mm}$ to $0.85 \mathrm{~mm}$ where the utilized element size was $0.1 \mathrm{~mm}$ in the simulations which was sufficient to capture the CZL accurately, i.e. at least 5 elements in the delamination direction. The increase in the CZL was due to the fact that the CZL is larger in Mode-II than in Mode-I $[32]$.

\subsection{Effect of interface strength and critical energy release rate}

As aforementioned in Section 1, the processing conditions have an affect on the material properties. In order to see the effect of variation in the interface strength $\left(t_{n}^{\circ}, t_{s}^{\circ}\right)$ and critical energy release rate $\left(G_{I c}\right.$ and $\left.G_{I I c}\right)$ on the CZL development, a parameter study was carried out. Fig. 16 shows the effect of varying $t_{n}^{\circ}=80,60,40 \mathrm{MPa}$ and $t_{s}^{\circ}=100,75,50 \mathrm{MPa}$ on the CZL development for Layup-1. As expected from Eq. 1 and 2, the CZL increased for lower interface strength values. The increase in CZL with respect to $x_{\max }$ becomes higher for lower interface strength values. The range of CZL was approximately 1.1-1.9 mm for $t_{n}^{\circ}=40 \mathrm{MPa}$ and $t_{s}^{\circ}=50 \mathrm{MPa} ; 0.7-1.2 \mathrm{~mm}$ for $t_{n}^{\circ}=60 \mathrm{MPa}$ and $t_{s}^{\circ}=75 \mathrm{MPa}$ and $0.45-0.85 \mathrm{~mm}$ 


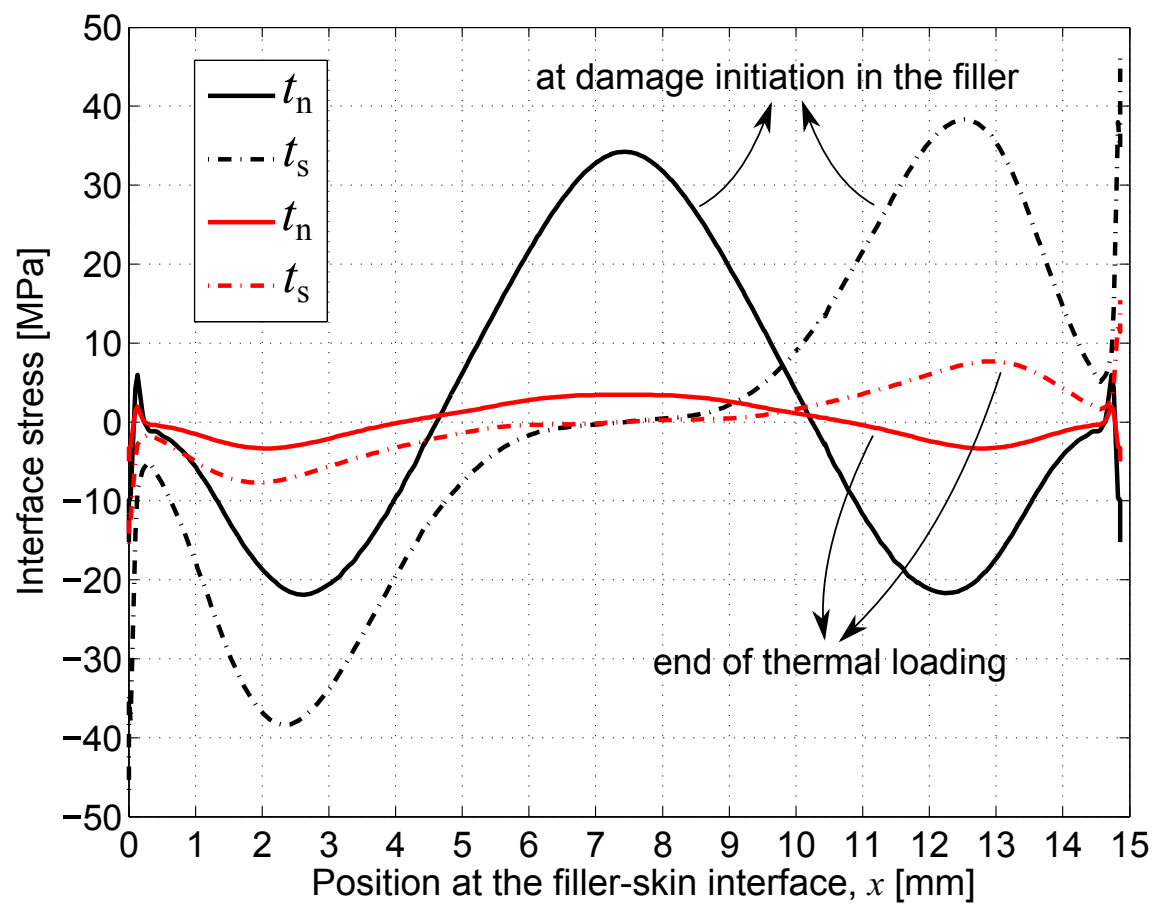

Figure 12: The interface stress distribution at the filler-skin interface after thermal loading and at damage initiation in the filler $\left(t_{n}^{\circ}=80 \mathrm{MPa}, t_{s}^{\circ}=100 \mathrm{MPa}\right)$.

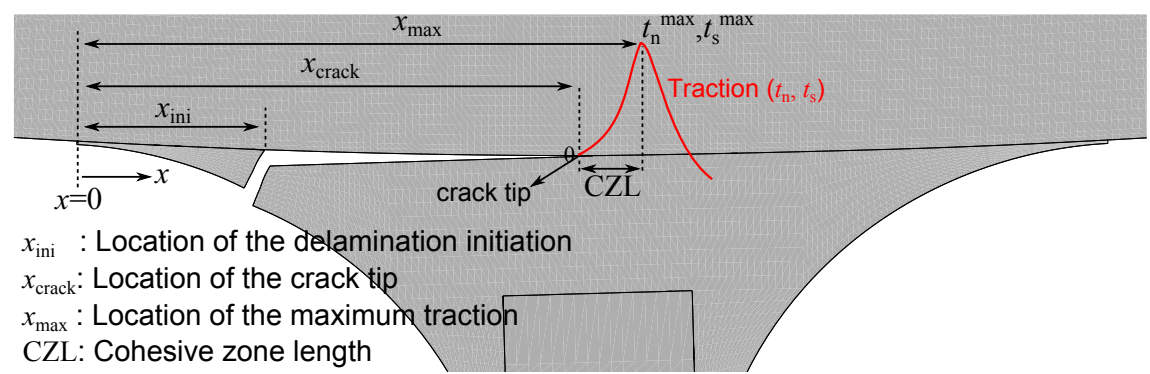

Figure 13: Schematic view of the distribution of traction ahead of crack tip.

for $t_{n}^{\circ}=80 \mathrm{MPa}$ and $t_{s}^{\circ}=100 \mathrm{MPa}$. Longer CZL in the simulations might result in significant inaccuracies in the numerical results [32]. However, the load-displacement curves were not affected by the change in $t_{n}^{\circ}$ and $t_{s}^{\circ}$ in the present study.

The effect of $G_{I c}$ and $G_{I I c}$ on the CZL is shown in Fig. 17 for different $t_{n}^{\circ}$ and $t_{s}^{\circ}$ values. It is seen that the largest CZL range during delamination was obtained for $G_{I c}=1.938$ $\mathrm{N} / \mathrm{mm}$ and $G_{I I c}=3.438 \mathrm{~N} / \mathrm{mm}$ for each interface strength values: approximately $2.75-3 \mathrm{~mm}$ 


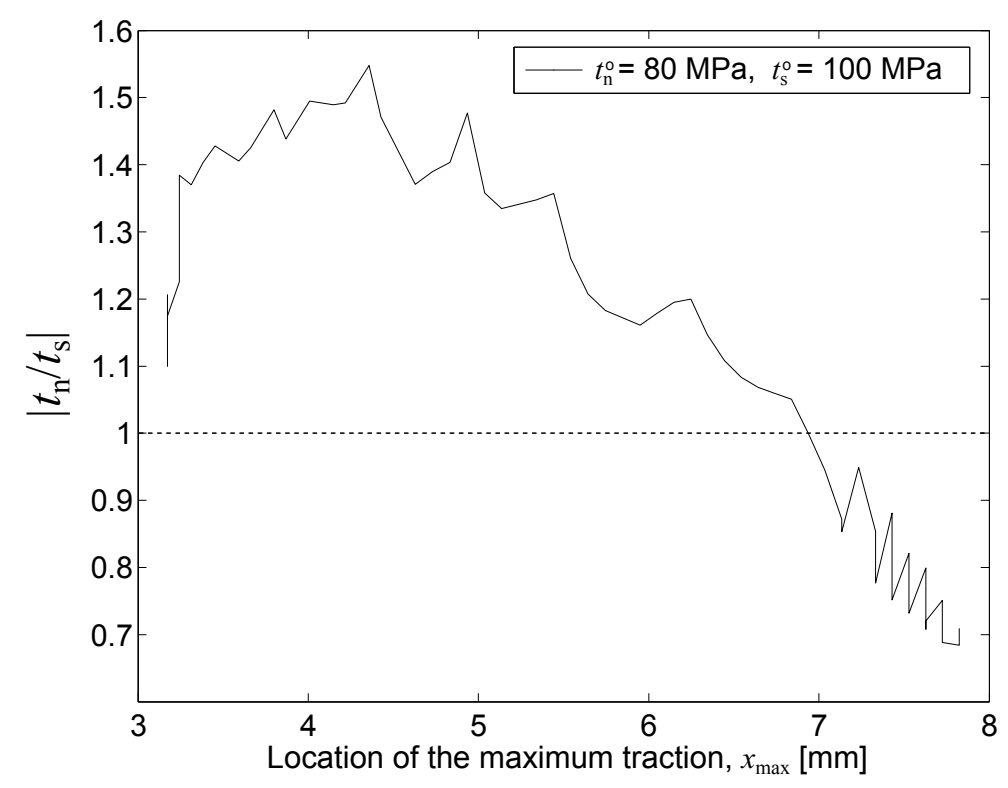

Figure 14: Development of the ratio of maximum traction $\left|t_{n} / t_{s}\right|$ during delamination for Layup-1.

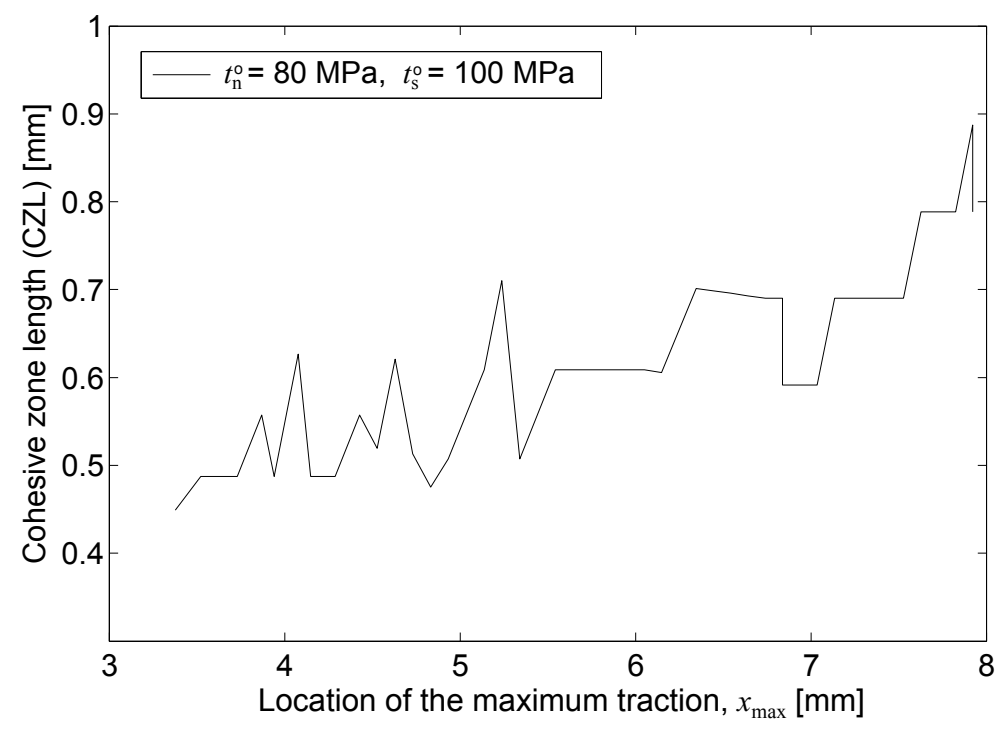

Figure 15: Predited CZL development during delamination as a function of $x_{\max }$ for Layup-1.

for $t_{n}^{\circ}=40 \mathrm{MPa}$ and $t_{s}^{\circ}=50 \mathrm{MPa} ; 1.6-1.8 \mathrm{~mm}$ for $t_{n}^{\circ}=60 \mathrm{MPa}$ and $t_{s}^{\circ}=75 \mathrm{MPa}$ and 1.1-1.2 $\mathrm{mm}$ for $t_{n}^{\circ}=80 \mathrm{MPa}$ and $t_{s}^{\circ}=100 \mathrm{MPa}$. An increase in $G_{I c}$ and $G_{I I c}$ resulted in larger CZL with a smaller force drop during delamination, hence a shorter delamiantion length. The corresponding force-displacement response is shown in Fig. 18. The force drop of approximately $70 \mathrm{~N}, 110 \mathrm{~N}$ and $120 \mathrm{~N}$ were obtained for $G_{I c}=1.938,0.969$ and $0.485 \mathrm{~N} / \mathrm{mm}$ 
and $G_{I I c}=3.438,1.719$ and $0.860 \mathrm{~N} / \mathrm{mm}$, respectively. This shows that simulation with too high critical energy release rate used at the cohesive surface was unable to capture the measured force drop and remaining stiffness of the butt joint. It was also found that there was very small influence of interface strength on the force drop as seen in Fig. 18.

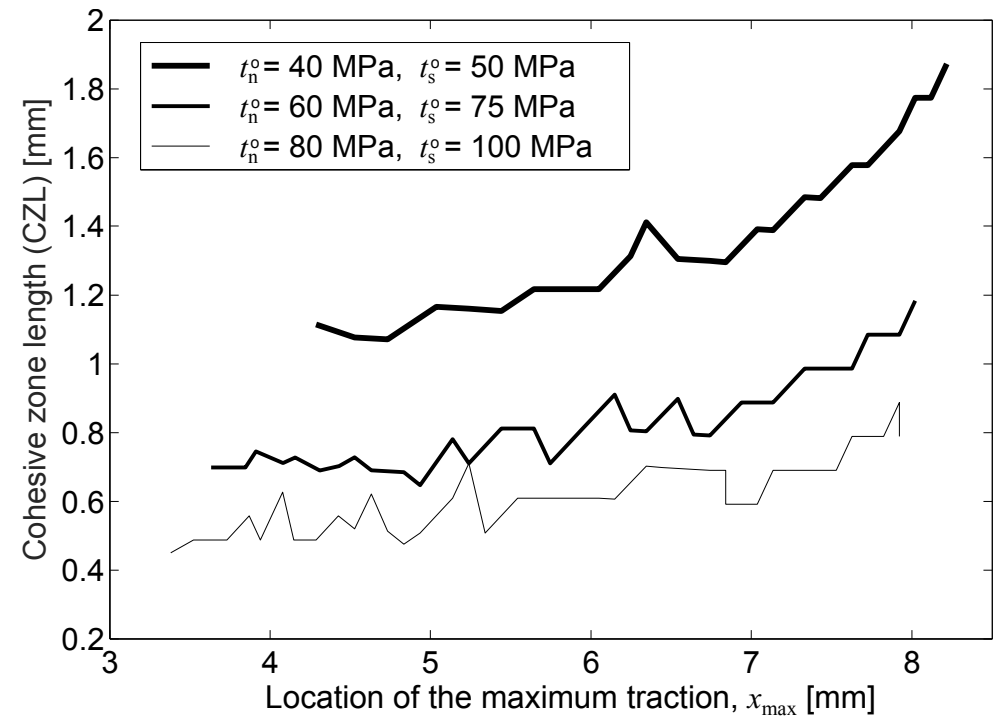

Figure 16: Effect of interface strength defined at the cohesive surface on the development of CZL during delamination for Layup-1. Note that $G_{I c}=0.969 \mathrm{~N} / \mathrm{mm}$ and $G_{I I c}=1.719 \mathrm{~N} / \mathrm{mm}$.

\section{Conclusions}

The critical assessment of the failure and CZL was presented in this study for a coconsolidated hybrid $\mathrm{C} / \mathrm{PEKK}$ butt joint. The failure under 3PB conditions was analyzed experimentally and numerically. The unstable crack growth in the short fiber $\mathrm{C} / \mathrm{PEKK}$ filler and the delamination at the filler-skin interface were captured using a high speed camera. It was found that the crack in the filler grew towards this interface in less then $33 \mu$ s and the delamination tok place within 1-2 ms. The observed failure behavior was simulated using a coupled XFEM-CZM approach in ABAQUS.

A good agreement between the experimental results and the numerical predictions was obtained for the butt joint. The predicted stiffness of the specimen, the location of crack initiation and propagation as well as force drop during delamination were in good agree- 


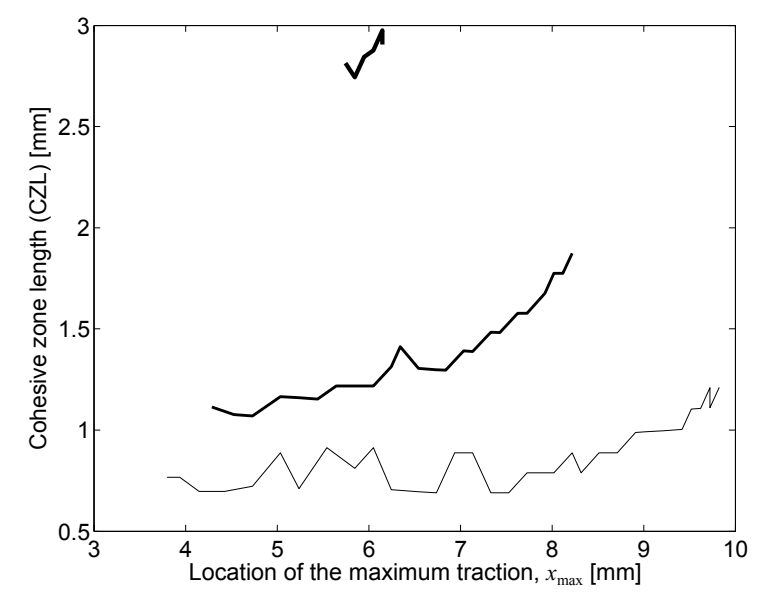

a) $t_{\mathrm{n}}^{\circ}=40 \mathrm{MPa}, t_{\mathrm{s}}^{\circ}=50 \mathrm{MPa}$

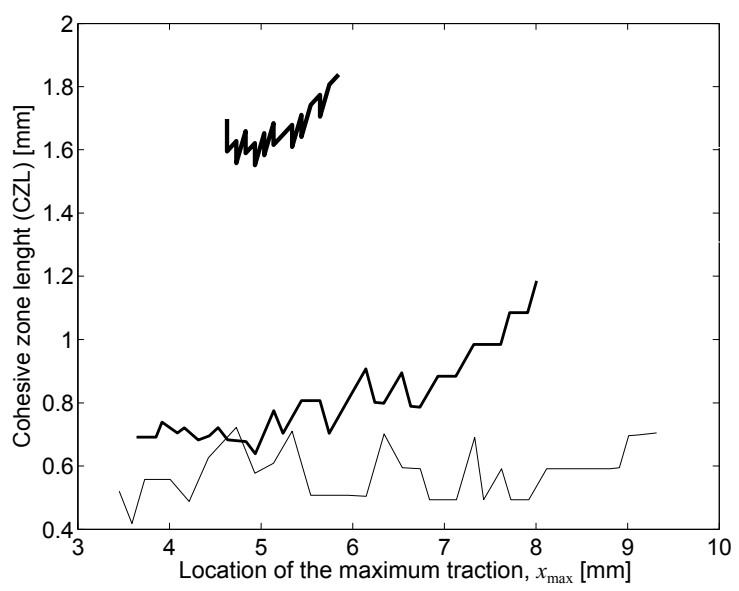

b) $t_{\mathrm{n}}^{\circ}=60 \mathrm{MPa}, t_{\mathrm{s}}^{\circ}=75 \mathrm{MPa}$
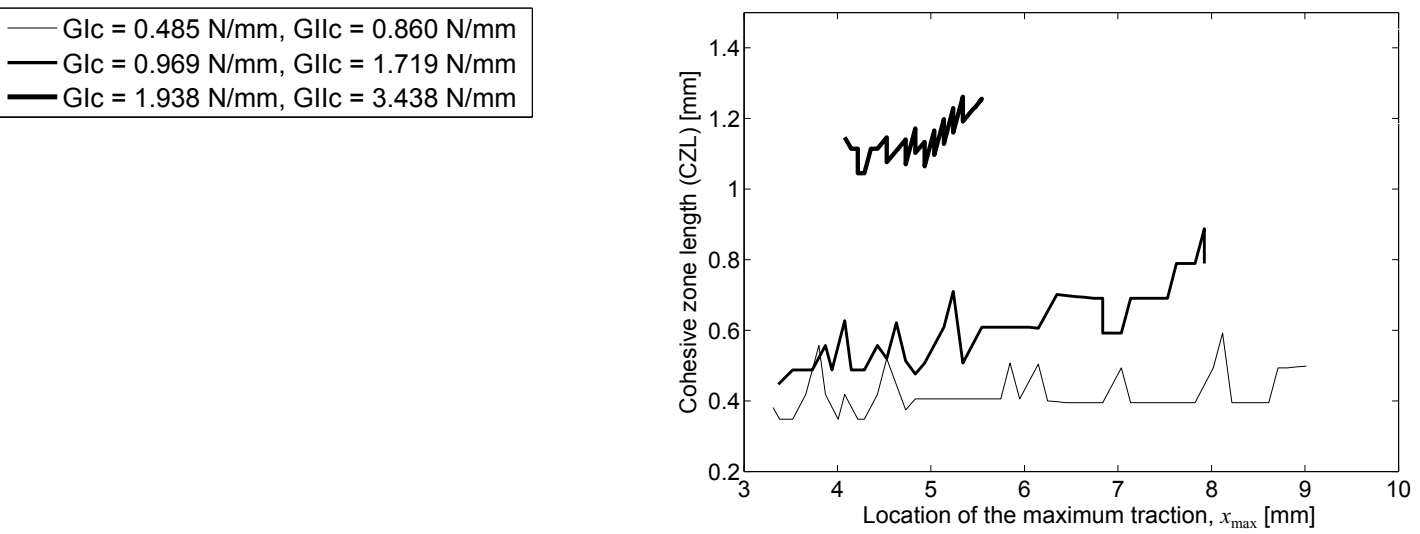

c) $t_{\mathrm{n}}^{\circ}=80 \mathrm{MPa}, t_{\mathrm{s}}^{\circ}=100 \mathrm{MPa}$

Figure 17: Effect of critical strain energy release rate $\left(G_{I c}\right.$ and $\left.G_{I I c}\right)$ on the development of CZL during delamination for different interface strength values used at the cohesive surface for Layup-1.

ment with experimental data by taking the residual thermal stresses into account in the model.

The traction at the cohesive surface was found to vary during delamination due to the nature of the mix mode behavior of the interface. Mode-I opening was found to be dominant at the beginning of the delamination and Mode-II in-plane shear became more effective during the progression of delamination and near the end of delamination. This yielded in an increase in the CZL due to the fact that the CZL in Mode-II is in general larger than the 


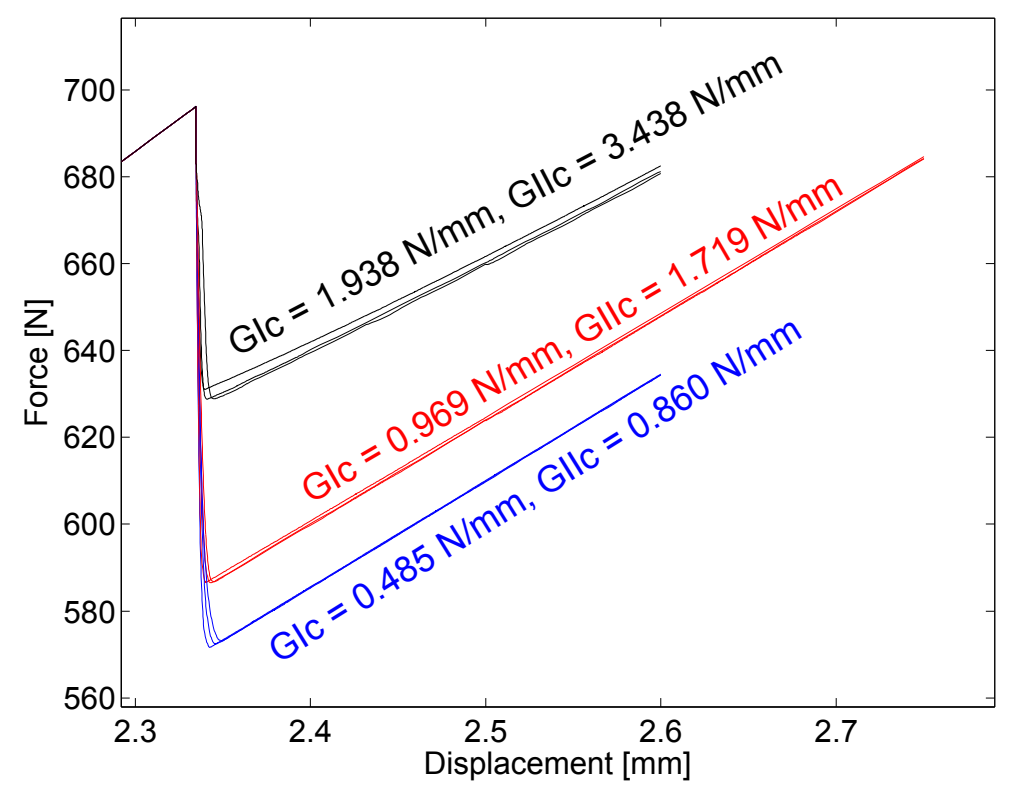

Figure 18: Effect of $G_{I c}$ and $G_{I I c}$ on the force-displacement response for different interface strength values used at the cohesive surface for Layup-1. Note that stiffness up to fracture is the same for all cases. The interface strength values are not labeled in the figure because the results are very close to each other based on certain $G_{I c}$ and $G_{I I c}$.

CZL in Mode-I [32].

A parameter analysis was carried out to investigate the effect of interface strength $\left(t_{n}^{\circ}\right.$ and $\left.t_{s}^{\circ}\right)$ and critical energy release rate $\left(G_{I c}\right.$ and $\left.G_{I I c}\right)$ on the CZL and force-displacement response of the butt joint. It was found that an increase in $G_{I c}$ and $G_{I I c}$ resulted in larger CZL with a smaller force drop during delamination and hence a shorter delamination length. There was hardly any effect of $t_{n}^{\circ}$ and $t_{s}^{\circ}$ on the delamination length and force drop found from the numerical simulations.

\section{References}

[1] SP Haanappel and R Akkerman. Shear characterisation of uni-directional fibre reinforced thermoplastic melts by means of torsion. Composites Part A: Applied Science and Manufacturing, 56:8-26, 2014.

[2] SP Haanappel, RHW Ten Thije, U Sachs, B Rietman, and R Akkerman. Formability analyses of uni-directional and textile reinforced thermoplastics. Composites Part A: Applied Science and Manufacturing, 56:80-92, 2014. 
[3] WJB Grouve, LL Warnet, and R Akkerman. Critical assessment of the mandrel peel test for fiber reinforced thermoplastic laminates. Engineering fracture mechanics, 101:96-108, 2013.

[4] WJB Grouve, G Vanden Poel, LL Warnet, and R Akkerman. On crystallisation and fracture toughness of poly (phenylene sulphide) under tape placement conditions. Plastics, Rubber and Composites, $42(7): 282-288,2013$.

[5] Benoit Landry and Pascal Hubert. Experimental study of defect formation during processing of randomly-oriented strand carbon/peek composites. Composites Part A: Applied Science and Manufacturing, 77:301-309, 2015.

[6] Dipa Ray, Anthony J Comer, John Lyons, Winifred Obande, David Jones, Ronan MO Higgins, and Michael A McCarthy. Fracture toughness of carbon fiber/polyether ether ketone composites manufactured by autoclave and laser-assisted automated tape placement. Journal of Applied Polymer Science, 132(11):1-10, 2015.

[7] Woo I Lee, Margaret F Talbott, George S Springer, and Lars A Berglund. Effects of cooling rate on the crystallinity and mechanical properties of thermoplastic composites. Journal of Reinforced Plastics and Composites, 6(1):2-12, 1987.

[8] Shang-Lin Gao and Jang-Kyo Kim. Cooling rate influences in carbon fibre/peek composites. part ii: interlaminar fracture toughness. Composites Part A: Applied science and manufacturing, 32(6):763$774,2001$.

[9] Margaret F Talbott, George S Springer, and Lars A Berglund. The effects of crystallinity on the mechanical properties of peek polymer and graphite fiber reinforced peek. Journal of Composite Materials, 21(11):1056-1081, 1987.

[10] Pedro P Camanho and Carlos G Dávila. Mixed-mode decohesion finite elements for the simulation of delamination in composite materials. 2002.

[11] Pedro Ponces Camanho, CG Davila, and ST Pinho. Fracture analysis of composite co-cured structural joints using decohesion elements. Fatigue $\&$ fracture of engineering materials $\&$ structures, 27(9):745$757,2004$.

[12] J.F. Chen, E.V. Morozov, and K. Shankar. Simulating progressive failure of composite laminates including in-ply and delamination damage effects. Composites Part A: Applied Science and Manufacturing, 61:185-200, 2014.

[13] Liang Wang, Chuanxiang Zheng, Hongying Luo, Shuang Wei, and Zongxin Wei. Continuum damage modeling and progressive failure analysis of carbon fiber/epoxy composite pressure vessel. Composite Structures, 134:475-482, 2015.

[14] A Atas, GF Mohamed, and C Soutis. Modelling delamination onset and growth in pin loaded composite laminates. Composites Science and Technology, 72(10):1096-1101, 2012. 
[15] A Ataş and C Soutis. Application of cohesive zone elements in damage analysis of composites: Strength prediction of a single-bolted joint in cfrp laminates. International Journal of Non-Linear Mechanics, 66:96-104, 2014.

[16] F Bianchi, TM Koh, X Zhang, IK Partridge, and AP Mouritz. Finite element modelling of z-pinned composite t-joints. Composites Science and Technology, 73:48-56, 2012.

[17] A Riccio, A Raimondo, G Di Felice, and F Scaramuzzino. A numerical procedure for the simulation of skin-stringer debonding growth in stiffened composite panels. Aerospace Science and Technology, 39:307-314, 2014.

[18] Li Jun, Xiao Yu Liu, Yuan Ya Nan, and Yao Xuefeng. Numerical and experimental analysis of delamination in the t-stiffener integrated composite structure. Mechanics of Advanced Materials and Structures, 23(10):1188-1196, 2016.

[19] Hai Wu, Jiayu Xiao, Suli Xing, Siwei Wen, Fubiao Yang, and Jinshui Yang. Numerical and experimental investigation into failure of t700/bismaleimide composite t-joints under tensile loading. Composite Structures, 130:63-74, 2015.

[20] S Heimbs, AC Nogueira, E Hombergsmeier, M May, and J Wolfrum. Failure behaviour of composite t-joints with novel metallic arrow-pin reinforcement. Composite Structures, 110:16-28, 2014.

[21] H Gulasik and D Coker. Delamination-debond behaviour of composite t-joints in wind turbine blades. In Journal of Physics: Conference Series, volume 524, page 012043. IOP Publishing, 2014.

[22] Ronald Krueger and Pierre J Minguet. Analysis of composite skin-stiffener debond specimens using a shell/3d modeling technique. Composite structures, 81(1):41-59, 2007.

[23] E Fo Rybicki and MF Kanninen. A finite element calculation of stress intensity factors by a modified crack closure integral. Engineering Fracture Mechanics, 9(4):931-938, 1977.

[24] EF Rybicki, DW Schmueser, and J Fox. An energy release rate approach for stable crack growth in the free-edge delamination problem. Journal of Composite Materials, 11(4):470-487, 1977.

[25] Ronald Krueger, Isabelle L Paris, T Kevin O'Brien, and Pierre J Minguet. Comparison of 2d finite element modeling assumptions with results from $3 \mathrm{~d}$ analysis for composite skin-stiffener debonding. Composite Structures, 57(1):161-168, 2002.

[26] Ronald Krueger. Virtual crack closure technique: history, approach, and applications. Applied Mechanics Reviews, 57(2):109-143, 2004.

[27] H Hosseini-Toudeshky, B Mohammadi, B Hamidi, and HR Ovesy. Analysis of composite skin/stiffener debounding and failure under uniaxial loading. Composite Structures, 75(1):428-436, 2006.

[28] Guillermo Vigueras, Federico Sket, Cristobal Samaniego, Ling Wu, Ludovic Noels, Denny Tjahjanto, Eva Casoni, Guillaume Houzeaux, Ahmed Makradi, Jon M Molina-Aldareguia, et al. An xfem/czm implementation for massively parallel simulations of composites fracture. Composite Structures, 125:542- 
$557,2015$.

[29] Lyazid Bouhala, Ahmed Makradi, Salim Belouettar, Anis Younes, and Sundararajan Natarajan. An xfem/czm based inverse method for identification of composite failure parameters. Computers 8 Structures, 153:91-97, 2015.

[30] Wei Tan and Brian G Falzon. Modelling the nonlinear behaviour and fracture process of as4/pekk thermoplastic composite under shear loading. Composites Science and Technology, 126:60-77, 2016.

[31] Gang Li and Chun Li. Assessment of debond simulation and cohesive zone length in a bonded composite joint. Composites Part B: Engineering, 69:359-368, 2015.

[32] Paul W Harper and Stephen R Hallett. Cohesive zone length in numerical simulations of composite delamination. Engineering Fracture Mechanics, 75(16):4774-4792, 2008.

[33] A Soto, EV González, P Maimí, A Turon, JR Sainz de Aja, and FM de la Escalera. Cohesive zone length of orthotropic materials undergoing delamination. Engineering Fracture Mechanics, 159:174-188, 2016.

[34] Albert Turon, Carlos G Davila, Pedro Ponces Camanho, and J Costa. An engineering solution for mesh size effects in the simulation of delamination using cohesive zone models. Engineering fracture mechanics, 74(10):1665-1682, 2007.

[35] Michael May and Torsten Lässig. Rate-dependent mode i delamination in ballistic compositesexperiment and simulation. Composite Structures, 180:596-605, 2017.

[36] BSEN ISO. 527-2: 1996. plasticsdetermination of tensile propertiespart 2: test conditions for moulding and extrusion plastics. British Standards Institution, pages 1-14, 1996.

[37] John Anthony Pickhaver. Numerical modelling of building response to tunnelling. University of Oxford, 2006.

[38] F Gruttmann and W Wagner. Shear correction factors in timoshenko's beam theory for arbitrary shaped cross-sections. Computational Mechanics, 27(3):199-207, 2001.

[39] Patricia P Parlevliet, Harald EN Bersee, and Adriaan Beukers. Residual stresses in thermoplastic compositesa study of the literaturepart i: Formation of residual stresses. Composites Part A: Applied Science and Manufacturing, 37(11):1847-1857, 2006.

[40] I. Baran, K. Cinar, N. Ersoy, R. Akkerman, and J. H. Hattel. A review on the mechanical modeling of composite manufacturing processes. Archives of Computational Methods in Engineering, pages 1-31, 2016.

[41] ML Benzeggagh and M Kenane. Measurement of mixed-mode delamination fracture toughness of unidirectional glass/epoxy composites with mixed-mode bending apparatus. Composites science and technology, 56(4):439-449, 1996.

[42] P.P. Camanho, C.G. Davila, and M. F. De Moura. Numerical simulation of mixed-mode progressive delamination in composite materials. Journal of composite materials, 37(16):1415-1438, 2003. 
[43] Wilhelmus J Vankan, Bas HAH Tijs, Gerrit J de Jong, Herman C de Frel, and Niels K Singh. Strength of notched and un-notched thermoplastic composite laminate in biaxial tension and compression. Journal of Composite Materials, 50(25):3477-3500, 2016.

[44] Technical data sheet: Pekk thermoplastic polymer. Technical report, CYTEC, 2012.

[45] Seyyedvahid Mortazavian and Ali Fatemi. Effects of fiber orientation and anisotropy on tensile strength and elastic modulus of short fiber reinforced polymer composites. Composites Part B: Engineering, 72:116-129, 2015.

[46] Patricia P Parlevliet, Harald EN Bersee, and Adriaan Beukers. Residual stresses in thermoplastic compositesa study of the literaturepart ii: Experimental techniques. Composites Part A: Applied Science and Manufacturing, 38(3):651-665, 2007.

[47] Patricia P Parlevliet, Harald EN Bersee, and Adriaan Beukers. Residual stresses in thermoplastic composites-a study of the literature. part iii: Effects of thermal residual stresses. Composites Part A: Applied Science and Manufacturing, 38(6):1581-1596, 2007.

[48] TJ Chapman, JW Gillespie Jr, RB Pipes, J-AE Manson, and JC Seferis. Prediction of process-induced residual stresses in thermoplastic composites. Journal of Composite Materials, 24(6):616-643, 1990.

[49] Fazil O Sonmez, H Thomas Hahn, and Mustafa Akbulut. Analysis of process-induced residual stresses in tape placement. Journal of Thermoplastic Composite Materials, 15(6):525-544, 2002. 